\title{
Tropical Cyclones and Post-Disaster Reconstruction of Public Infrastructure in Developing Countries*
}

July 4, 2020

\author{
Christopher Adam \\ christopher.adam@qeh.ox.ac.uk \\ and \\ David Bevan \\ david.bevan@sjc.ox.ac.uk \\ University of Oxford, UK
}

\begin{abstract}
When natural disasters destroy public capital, these direct losses are exacerbated by indirect losses arising from reduced private output during reconstruction. These may be large in developing countries that lack access to external finance. We develop a general equilibrium model of a small open economy that highlights the relation between public infrastructure and private capital, to examine the effects of natural disasters and alternative reconstruction paths. Calibrating the model to data from the Caribbean Catastrophic Risk Insurance Facility (CCRIF), we examine alternative post-disaster financing mechanisms including reserve depletion, budget reallocation, sovereign disaster insurance, debt and taxation. Disaster insurance is shown to play a limited role in financing reconstruction, while budget re-allocations are potentially damaging especially if they cannibalize operations and maintenance expenditures. Absent donor grants or concessional borrowing, tax financing - where feasible - remains the least damaging financing instrument, particularly if the country risk premium on external debt is high.
\end{abstract}

JEL Codes: H54, Q54, E60

${ }^{*}$ This paper is based on work carried out for the World Bank's Global Facility for Disaster Reduction and Recovery, with funding from the UK Department for International Development (see Bevan and Adam, 2016). We are particularly grateful to Daniel Clarke and Richard Poulter for their advice and guidance. We thank Samantha Cook, Stephen Hallegatte, Alejandro Guerson, Wendell Samuel, Willi Semmler and to two referees for extremely valuable comments on earlier drafts, and to conference participants at the OCP Policy Centre "Coping with Climate Change" workshop in Paris, October 1, 2018. Radhika Goyal and Sterre Kuipers provided excellent research assistance. All errors and omissions are our own. 


\section{Introduction}

When natural disasters strike, attention tends to focus primarily on the loss of lives and livelihoods, the loss of output and the destruction of private dwellings and factories. Public policy will often, correctly, prioritize the humanitarian response by seeking to secure basic livelihoods in the short run and restore private activity over the medium term. But natural disasters destroy public infrastructure capital just as readily as they do private capital, and possibly more so if the public capital stock is less physically resilient and/or more exposed to natural hazards. The key feature of public capital is its complementarity with private factors of production; the destruction of public capital, therefore, not only lowers current private output but also lowers the ex ante expected return to private capital and labour, so that the loss of public capital blunts the private sector's incentives to rebuild. Both effects are magnified the more important are the network properties of public capital. By the same token, the speed with which the public capital stock is restored post-disaster plays a decisive role in determining the recovery in private output and consumption. The speed of rebuild is only one element of the reconstruction, however. The other is how reconstruction is financed. In practice, small disaster-prone developing countries face a limited range of options, particularly since access to external debt markets in the wake of natural disasters is expensive, often prohibitively so.

Unless development assistance (in the form of quick-disbursing donor grants) is forthcoming, the public finance choice reduces to four options, which may be pursued separately or in combination. The first is to rely on domestic financing. This may involve the draw-down of accumulated foreign exchange reserves and/or domestic debt financing in the short-run, but ultimately it means relying on domestic taxation, the growth impact of which depends on how distortionary the tax system is. Subject to the same public finance considerations, the second option is to secure external commercial debt finance, to the extent possible given that developing countries are likely to face a very sharply rising external risk premium in post-disaster environments. The third option is to finance reconstruction by re-allocating public expenditure from other uses, including from the operations and maintenance expenditures on the surviving public capital stock. Finally, the country may be able to take out catastrophic disaster risk insurance with private providers. With insurance purchased and in place, the direct costs of the rebuild can be met without the need to raise taxes or reallocate expenditures. In addition, market-based insurance may be bundled with forms of technical expertise so that the maximum rebuild rate can be faster than if reconstruction is wholly tax- or debt-financed. Against this, of course, must be set the cost of carrying insurance which itself needs to be financed from the (distortionary) domestic tax system.

In this paper we examine the consequences of natural disasters and the post-disaster reconstruction of public capital for the macroeconomic dynamics of a small open economy under these alternative public finance strategies. We make two specific contributions. First, we modify a 
standard calibrated dynamic general equilibrium model to highlight the network characteristics of public infrastructure capital and use this to conduct an impulse-response analysis of the effects of the destruction of public capital and the subsequent adjustment of the economy following a specific natural disaster. Second, we then use this framework to conduct a welfare analysis across a range of feasible reconstruction-financing strategies available to disaster-prone small developing countries. To make this concrete, we calibrate the model to data from Jamaica, one of the many small Caribbean island nations vulnerable to tropical cyclones (hurricanes) originating in the Atlantic Ocean. Annual average losses from cyclone damage in Jamaica are estimated at around $0.5 \%$ of GDP, with periodic very large losses, the largest in the recent past being Hurricane Gilbert in 1988 where estimated total losses were $9.6 \%$ of GDP. ${ }^{1}$ Our calibration of the disaster risks facing the model economy is based on data compiled by the Caribbean Catastrophe Risk Insurance Facility (CCRIF), of which Jamaica is a participating member.

To focus on the principal mechanisms of interest, namely the complementarity between public and private capital, and on the consequences of alternative financing strategies we adopt the following simplifying steps, each of which can, in principle, be relaxed in future work.

First, we limit our attention to the case where cyclone damage is entirely concentrated on the physical capital stocks in the economy, both public and private. Thus we assume that no lives are lost nor is current output lost directly as a result of this hazard. Hence, the entire impact on private output and consumption comes solely through the loss of the capital stock, both the sector-specific private capital and complementary public infrastructure capital. For example, we may think of this hypothetical cyclone destroying not just factories and buildings but also roads or key bridges, port infrastructure, or bringing down power transmission lines. Within our modeling framework, it is straightforward to model the disaster in a more complex manner, allowing for temporary interruptions to the labour market and to current production. However, our purpose in this paper is to think about the public finance dynamics of destruction and reconstruction and the role of sovereign disaster risk insurance; the characterization used here is sufficient to identify the key considerations relevant to doing so.

Second, we do not provide for an explicit treatment of disaster-risk insurance provision to the private sector in this model. In part this reflects reasons of analytical tractability, but it is also in fact an accurate reflection of the extremely low levels of insurance cover against natural disasters held by the private sector in many developing countries, including Jamaica (see, for example, Noy et al, 2017 and World Bank, 2018, Chapter 4.) ${ }^{2}$

Third, to analyse the dynamic macroeconomic response of the economy to natural disasters, we employ an impulse-response approach in which the economy is subject to a single natural disaster of a particular size. Thus, the consequences for a range of shock intensities can be

\footnotetext{
${ }^{1}$ See Jamaica: Hurricanes and Earthquakes Risk Profile World Bank (2016).

${ }^{2}$ Although we do not have explicit private sector insurance in the model, we do allow for transfers to the private sector to play a role in the public policy response to the natural disaster; these can be thought of as a form of partial ex post insurance of household consumption.
} 
compared under alternative public finance responses, providing the basis of our welfare analysis. We discuss this approach and its limitations in more detail in Section 3.

The model tracks the direct damage to public and private capital assets as well as output losses, often termed "indirect" losses, attributable to the attenuated process of reconstruction following a natural disaster. These consist of output losses caused by the reduced capital stocks and also the output costs attributed to the cost of raising the financing for reconstruction, be that through taxation, debt or insurance. ${ }^{3}$ The primary focus of this paper is how the indirect losses along a recovery path can be mitigated by various financing mechanisms and our analysis highlights the rather unappealing menu of financing choices countries face if they are unable to secure significant quick-disbursing grant financing: external debt is expensive, especially if the debtor country must pay a strongly pro-cyclical country risk premium, as is marketbased insurance, unless it can rapidly accelerate the rebuilding process. By contrast, domestic financing may be less expensive, especially if domestic taxation is not highly distortionary. But absent debt financing, tax financing can exacerbate the powerful recessionary effects of natural disasters since taxation is required to increase just as productive capacity is destroyed. A natural alternative is to re-allocate existing public expenditure towards reconstruction, although this risks undermining the recovery if recurrent expenditures are allocated away from the operations and maintenance of public capital.

The remainder of the paper is as follows. Section 2 describes the basic features of the model. Section 3 describes the model's calibration, details the method we employ to characterize the profile of natural disaster risks faced by the economy and conduct the welfare analysis. Section 4 then discusses the model simulations and the associated welfare analysis. Section 5 concludes with some implications for policy.

\section{The Model}

Our model is based on the dynamic general equilibrium model developed by Buffie et al (2012), extended in Melina et al (2016) and published as Zanna et al (2019). As the model is well-known, we relegate most of the model details to Appendix I and limit the discussion here to the principal modifications required to examine the consequences of the destruction and reconstruction of physical capital. 4 These are the characterization of production and the modeling of public capital, including the central role of its operations and maintenance expenditures; and the public financing choices of the government in post-disaster reconstruction.

The core model describes a small open two-sector economy. Production in each sector (tradables and non-tradables) is a function of public and private capital, labour and a steadily-

\footnotetext{
${ }^{3}$ The model is capable of tracking other temporary or persistent output losses additional to those reflecting the asset losses themselves. These could reflect damage to assets such as land or to social capital or institutional capital, or to migration or other losses of effective labour. We choose not to consider these effects in this paper.

${ }^{4}$ MATLAB codes are available on request from the authors.
} 
growing total factor productivity. Production is carried out by competitive, price-taking firms operating under constant returns to the private factors, and increasing returns in the presence of public capital. Labour is mobile between the sectors. Households maximize an additive inter-temporal utility function; a fraction of households have access to financial markets and are able to smooth consumption over time, but the remainder are credit constrained so that their current consumption is fully determined by their current income. There are no nominal assets and no nominal rigidities and hence no role for monetary policy.

Government makes transfers to households that may be state-contingent, and provides public infrastructure capital, which requires recurrent expenditure on operations and maintenance $(\mathrm{O} \& \mathrm{M})$. Critically, reductions in operations expenditures reduce the contribution of the installed public capital to private productivity, while reductions in maintenance expenditures accelerate the depreciation of the public capital stocks (see Adam and Bevan, 2014). The government may also accumulate official foreign reserves for self-insurance purposes and contract contingent disaster finance or insurance facilities. Government spending is financed by taxation and public debt, with the former levied on capital and labor incomes (at a common rate) and/or on consumption. Given the behaviour of firms and households, these taxes are distortionary and impose deadweight losses on the private sector. Finally, public debt may be domestic or external; in the latter case the country faces a country risk premium that is (sharply) increasing in net public indebtedness. ${ }^{5}$

\subsection{Public capital and private production}

A conventional Cobb-Douglas specification of the complementarity between public and private factors defines production in each sector as

$$
q_{j, t}=a_{j, t}\left(z_{t-1}\right)^{\psi_{j}}\left(k_{j, t-1}\right)^{\alpha_{j}}\left(L_{j, t}\right)^{1-\alpha_{j}}
$$

where $j=N, T$ for non-tradable and tradable sector, $z_{t-1}$ is public capital and $\psi_{j}>0$ measures the extent of increasing returns generated by public infrastructure in each sector. However, this specification, whilst convenient, is not well equipped to study the idea that losses of public capital through natural disasters might be seriously damaging when there are strong complementarities between public and private factors, for two reasons. First, a given percentage reduction in the public capital stock causes a rather attenuated reduction in output. For example, based on a standard calibration with the capital share, $\alpha_{j}=0.4$ and the elasticity of output to public capital, $\psi_{j}=0.2$, the elimination of 20 of the public capital stock would lower steady-state output by only $4.4 \%$. Moreover, this attenuated percentage reduction is uniform, regardless of how inadequate or indeed excessive was the level of the initial public capital stock. To

\footnotetext{
${ }^{5}$ In either case, long-run debt sustainability holds so that explosive paths for domestic and external debt are ruled out. By design, both debt stocks converge back to their initial ratios of GDP.
} 
better reflect the network nature of public capital we modify this conventional treatment of the complementarity of public and private capital in two ways.

First, we suppose that there are two components of public capital, $z_{1}$ and $z_{2}$ - 'bridges and roads' - which are combined to form the aggregate $\tilde{z}$; this aggregation is done via a CES function, so

$$
\tilde{z}=\left(\gamma^{1 / \varepsilon z} z_{1}^{1-1 / \varepsilon z}+(1-\gamma)^{1 / \varepsilon z} z_{2}^{1-1 / \varepsilon z}\right)^{1 /(1-1 / \varepsilon z)}
$$

where $\varepsilon z$ is the elasticity of substitution between the two components of public capital. The composite $\tilde{z}$ now enters the production function in place of a unitary $z$. If $\varepsilon z$ tends to infinity, the two components are perfect substitutes, and the composition of public investment is irrelevant; if $\varepsilon z=1$, the aggregator is itself Cobb-Douglas; if $\varepsilon z=0$, they are perfect complements, and the level of composite public capital is entirely determined by the component that is in shorter supply, relative to the efficient ratio of $z_{1} / z_{2}=\gamma /(1-\gamma)$.

Second, there may be a threshold effect for public capital, embodied in $\bar{z}$, before it becomes productive. One could think of a network, such as a road system, where odd bits of road make very little contribution to output, but a connected system does. Thus the sectoral production functions used in the model are

$$
q_{j, t}=a_{j, t}\left(z_{t-1}-\bar{z}\right)^{\psi_{j}}\left(k_{j, t-1}\right)^{\alpha_{j}}\left(L_{j, t}\right)^{1-\alpha_{j}}
$$

Table 1 shows how, for the baseline parameterization of the simulation model, variations in the degree of substitutability between the components of public capital, and the existence or otherwise of a threshold effect increase the output effect of any given assault on public capital. We consider six cases. Substitutability may be low at an elasticity of 0.25 , effectively perfect (approximated by an elasticity of 1000), or take the intermedate Cobb Douglas case (approximated by an elasticity of 0.999). In each case, there may be either no threshold effect, or one at $25 \%$ of the steady state stock.

\section{$<*$ Table 1 here ${ }^{* *}>$}

When the elasticity of substitution between the composite public good and private capital and between the components of the public capital stock is arbitrarily high and there is no threshold, $(\bar{z}=0)$, the output elasticity is 0.38 . If it is 0.25 and there is a threshold effect, this rises to 0.59 . The runs reported below assume the latter case. 


\subsection{Operations and Maintenance}

The costs of public investment are not restricted to the upfront capital cost and associated financing of construction and reconstruction; they also include ongoing recurrent costs for operations and maintenance, and since, even when adequately maintained, capital still depreciates, there will also be the cost of future replacement. To allow for inefficiencies in the operation and maintenance of public capital, we first distinguish between two different notions of public capital: installed capital $(z)$ as discussed above, and effective (or effectively productive) capital $\left(z^{e}\right)$,where the latter is defined as $z^{e}=\gamma_{p} z$ and $0<\gamma_{p} \leq 1$ is the ratio of actual to efficient operations expenditure. ${ }^{6}$ Deficient operations expenditure reduces the flow of output produced by the current stock of public capital. For simplicity, operations requirements are treated as being kinked at the efficient level; while there is an immediate loss involved when $\gamma$ is allowed to fall below 1 , there is no corresponding gain if $\gamma>1$ : excess expenditure of this kind is waste ('polishing the rails'). ${ }^{7}$

Deficient maintenance expenditure, on the other hand, leads to an increase in the rate at which the public capital stock depreciates through time. Specifically, we define the depreciation rate of (installed) public capital as

$$
\delta_{z}^{i}=\delta_{z}\left[1+\left(1-\gamma_{m}\right) \beta_{\delta}\right]
$$

where $0<\gamma_{m} \leq 1$ is the ratio of actual to efficient maintenance expenditure and $\beta_{\delta} \geq$ 0 is a measure of excess depreciation. Thus the rate of depreciation is bounded between $\delta_{z}$ when maintenance is at its efficient level and $\delta_{z}\left(1+\beta_{\delta}\right)$ when maintenance is neglected entirely. The accelerated loss of installed capital during a period when maintenance is inadequate is permanent. Both O\&M effects can be temporary so that a return to 'full' maintenance and operations expenditures restores the (technical minimum) depreciation rate and the full flow of output. $^{8}$

The scale of recurrent costs per dollar of investment varies very significantly with the type of investment, tending to be much higher for social than for economic infrastructure. In our calibration (see Appendix Table 1) we draw on the limited evidence provided by (Heller, 1991), setting efficient annual total O\&M costs to 5 cents per dollar of installed capital (equivalent to approximately $4.4 \%$ of GDP). For reasons ranging from the technical to the political, government is typically unable or unwilling fully to recover these recurrent costs through user charges. In

\footnotetext{
${ }^{6}$ It is straightforward to allow for corruption and/or other inefficiencies to drive a wedge between the investment in public capital and the quantum eventually installed. Given the focus of this paper we abstract from this potential distortion but see Zanna et al (2019) and Berg et al (2019) .

${ }^{7}$ Our calibration assumes $\gamma_{p} \leq 1$.

${ }^{8}$ The assumption of a linear relationship between operations expenditure and efficiency is a simplifying one: in practice, the capital stock may be so degraded as a result of deficient operations and maintenance expenditures that it is simply not possible to restore it to 'full' efficiency without rebuilding afresh.
} 
consequence, public investment creates recurrent fiscal burdens which must be financed; we turn to these next.

\subsection{Financing government expenditure in good times and post-disaster}

Given the purpose of this paper, we do not model government as an optimizing agent; rather we assume it makes exogenous decisions, or follows rules of thumb. Its capital program may be inefficient, both in the quality of public investment and in implementing the additional operations and maintenance expenditures that the program requires. These inefficiencies mean, respectively, that an additional dollar of public investment may not lead to an additional dollar of public capital being installed; that what capital is installed may not deliver its full level of services; and that installed capital may depreciate faster than it should. These inefficiencies may all worsen during a phase of accelerated investment, whether this is occasioned by an ambitious investment program or the need to replace destroyed assets, as discussed in this paper. There may also be adjustment costs during this phase, associated with capacity limitations in the private and public sectors, which raise the unit cost of investment.

The model provides for a fiscal reaction function that combines a long-run target for the domestic debt-to-GDP ratio with stickiness in the rate of adjustment of domestic taxation. This means that faced with an incipient financing gap, government will raise taxes and issue bonds in the short run to smooth tax adjustment, with taxation remaining elevated relative to its steady-state until domestic debt has returned to its steady state ratio. The details of these fiscal responses are outlined in Section 3.

\section{Calibration, Disaster Risks, and Simulation Design}

The model is calibrated to the macroeconomic structure of Jamaica for Financial Year 2013/14, drawing on national accounts data from the Statistical Institute of Jamaica (2015) and the IMF's 2014 Article IV Consultation. ${ }^{9}$ Appendix Table I summarizes this calibration and the key behavioural parameters of the model. Here we focus on the calibration of disasters and post-disaster reconstruction strategies.

\subsection{The characterization of disaster risk}

To reflect the hazard from natural disasters we draw on data from the Caribbean Catastrophic Risk Insurance Facility (https://www.ccrif.org/), the world's first multi-country natural disaster risk pool offering parametric insurance policies designed to mitigate short-term cash flow problems small developing economies suffer after major natural disasters. CCRIF's parametric

\footnotetext{
${ }^{9} \operatorname{IMF}(2014)$
} 
insurance mechanism allows it to provide rapid payouts to help member governments finance their initial disaster response and maintain basic government functions after a catastrophic event.

As noted, our approach is deterministic in the sense that it is designed to explore the properties of alternative policy responses to one or more specific natural disasters of a given magnitude. In order to conduct a welfare analysis of alternative financing strategies, however, we need to integrate the model with a characterization of the probability distribution of the scale of the disasters faced by the economy. In 2013, CCRIF published risk profiles (for tropical cyclones, excluding rainfall risk, and earthquakes) for twelve CCRIF members. ${ }^{10}$ These are shown in Figure 1 where aggregate direct losses associated with events of different magnitude are expressed in terms of GDP at official exchange rates. The profiles differ substantially in level, somewhat less in shape. In terms of the really high risk events, there seem to be three groups; first, a high risk group, (Dominica and Trinidad and Tobago) running at about 200\% of GDP; second, an intermediate group, (St Kitts, Antigua, Cayman Islands, and Bahamas) in the range $115 \%-150 \%$; and finally the remaining 6 countries in a relatively low risk group, in the range $37 \%-75 \%$.

\section{$<* *$ Figures 1 and 2 here ${ }^{* *}>$}

From these data, we compute a tractable continuous distribution that provides a reasonable approximate fit to these numbers plus the probability of 'no event' (see Appendix II). The risk profile is presented in Figure 2. In principle, with a well-defined parametric risk distribution, we could base our analysis on a standard Monte Carlo experiment. However, since we are dealing with a complicated dynamic model with a large range of possible policy responses against a background distribution defined over a broad event horizon spanning from zero to a rare 1-in-750 year risk event, running a Monte Carlo exercise sufficient to sample the relevant experimental space adequately would be prohibitively expensive. To reduce the dimensionality of the analysis we run the model for a small number of specific cases at a fixed set of points on the probability distribution and aggregate the results in a consistent fashion. Specifically, we analyze the model under shocks at the 1-in-10, 1-in-25, 1-in-50, 1-in-100, 1-in-250, 1-in-500 and 1-in-750 magnitudes. We compute probability weights associated with each of these shocks which give us a measure of the expected total capital losses associated with cyclone damage (see Table 2 and Appendix II).

$$
<* * \text { Table } 2 \text { here }{ }^{* *}>
$$

\footnotetext{
${ }^{10}$ Published risk profiles are available for Anguilla, Antigua and Barbuda, Bahamas, Belize, Bermuda, Cayman Islands, Dominica, St Kitts and Nevis, St Lucia, St Vincent and Grenadines, Trinidad and Tobago, and the Turks and Caicos. Those for Barbados, Grenada, Haiti, and Jamaica and not publicly available.
} 


\subsection{The time-line of destruction and recovery}

We assume the total destructive effect of cyclones is distributed across the private and public capital stocks $\left\{k_{x}, k_{n}\right.$ and the components of $\left.z\right\}$ according to their respective pre-shock shares in the total capital stock of the economy. The destruction of private capital is uniform across the two sectors; for public capital we assume the damage is concentrated exclusively on the relativey scarce component of the public aggregate, $z_{1}$.

The economy is initially in a (dynamic) steady state at time $t=0$. If the government takes any 'ex ante' actions, such as accumulating precautionary reserves or purchasing insurance, this takes place in $t=1$. The costs of these precautionary actions are met from distortionary domestic taxation. The cyclone then destroys public and private capital in $t=2$. We assume that recurrent public consumption transfers, if implemented, occur with immediate effect, but there is a lag before any public investment recovery programme can be put in place. These are are initiated at $t=3$ and associated public financing instruments are deployed and private investment responds so that from $t=4$, as capital reconstruction begins, output and consumption begin to recover. Private capital accumulation is defined by Tobin's $q$ where investment demand is driven by the anticipated future returns to capital across sectors relative to the cost of capital, where expected returns are a function, inter alia, of the stock of effective public capital. Private investment is subject to adjustment costs. Public capital on the other hand is rebuilt according to rules. We assume there are absorptive capacity constraints that limit the physical pace at which government working on its own can rebuild the public capital stock following a natural disaster (independent of its ability to finance higher public investment). We assume these constraints limit the feasible increase in gross public investment to $2 \%$ of initial GDP per annum. (Baseline aggregate public investment is just over $5 \%$ of GDP so this represents an approximately 40 percent increase in the public investment rate, post-disaster). Insurance in this model not only provides resources but if these are bundled with expertise and/or other inputs that allow for a faster physical pace of public reconstruction, the investment rate can increase by up to $4 \%$ of initial GDP per annum. With the post-disaster investment rate bounded at either the lower or higher level, the duration of the recovery phase is then determined by the magnitude of the destruction of public capital. For small shocks, those at the 1-in-25 year or less, the public capital stock is restored by the beginning of the second year following the cyclone. For shocks of the 1-in-100 case the capital stock is restored by the fifth year after the cyclone hits, while for the largest disasters considered here, the 1-in-750 case, the capital stock is restored by the start of the eighth year. By contrast in this final case, a 'do nothing' recovery path - which we describe in detail below - would see the capital stock recover only after 11 years post cyclone. With an accelerated recovery, the rebuild time is shortened for the larger shocks. 


\subsection{Financing instruments}

Government can deploy a wide array of instruments, either in isolation or in combination, to finance the capital costs of reconstruction. To keep the discussion manageable, we consider three basic financing programmes, exploring variations within each (see also Clarke et al., 2016). We focus exclusively on the financing of the reconstruction of public capital; in the cases discussed here, there is no specific subsidy to private capital reconstruction, although we do allow for public policy to include consumption transfers to the public sector. As noted above, we assume the private sector in aggregate has no capacity to insure against damage to private capital.

\section{Domestic Financing}

Our domestic financing package consists of four elements, although whether all are activated depends on the magnitude of the disaster. The detailed settings for the runs we describe in Section 4 are defined in Table 3: here we summarize the main elements.

- Reserve drawdown. When a hurricane hits, the draw-down of reserves represent the firstline financing response, unless insurance is in place. Reserves, the carrying cost of which is the spread between the interest cost on external debt and the 'world' risk-free rate earned on reserve assets, can be drawn down (to, but not beyond, zero) contemporaneously with investment spending. Reserves are gradually rebuilt back to their initial reserves-to-GDP ratio. ${ }^{11}$ We assume that precautionary reserves are sufficiently high to fully finance 1-in-10 shocks; thereafter they contribute to financing instruments but other instruments also need to be deployed.

- Consumption transfer To offset the adverse immediate effects of the loss of output and consumption in the wake of the natural disaster, the government may make short-run consumption transfers to households.

- Budget reallocation. A substantial part of post-disaster public financing typically comes from budget reallocation (see Bevan and Cook, 2015). We study the case where funds are diverted from operations and maintenance to reconstruction and rehabilitation. The diversion may be driven by budgetary constraints such as the difficulty of raising additional revenue or undertaking additional borrowing, or by real resource constraints the machinery and skilled labor that can reconstruct damaged bridges, for example, has to be drawn from the same pool as supplies bridge maintenance services. Operations and Maintenance (O\&M) spending is assumed to be at its efficient level initially but, following a natural disaster, the government may choose to reallocate budget expenditures to meet the cost of reconstruction. In the runs examined below we assume resources are diverted away from $O \& M$ expenditures on a pro rated basis, equally between operations

\footnotetext{
${ }^{11}$ The half-life to restoration of the reserves-to-GDP ratio is 5 years.
} 
and maintenance expenditures. Reductions in O\&M expenditures affect all vintages of public capital; already-installed capital and newly re-built capital is thus less effective and depreciates more rapidly during the re-build period than in the initial steady-state. When public capital has been restored to its initial steady-stake level (relative to GDP), O\&M expenditures are also restored to their initial steady-state levels.

- Taxation and domestic debt. The fiscal accounts are balanced by a combination of adjustments to tax rates and net sales of domestic government debt. Our fiscal financing rules require that the domestic debt ratio is anchored in the long run, but in the short-run debt can take some of the burden of financing. In the runs discussed below, we assume factor tax rates are held constant so that consumption taxes remain the residual financing item under all financing strategies. Thus even when government seeks to finance reconstruction through insurance or external debt, the consumption tax will adjust in the short-run to satisfy the fiscal balance when there are delays in disbursement of debt against public expenditures. Likewise consumption taxes will adjust in response to relative price movements that alter the ex post cost of capital and if delays in rebuild depress wages and profits and thereby undercut tax revenues from these sources. Consistent with the empirical literature (for example, Browning (1976), Ahmad and Stern (1984) and Auriol and Warlters (2012)), the consumption tax in this model is less distortionary than factor or output taxes so that the welfare costs of taxation represent a lower-bound on the tax distortion.

\section{External Debt Financing}

In reality, small economies may find themselves completely or partially excluded from private debt markets immediately post-disaster. To avoid having to model discrete jumps in market access we assume that countries can access private commercial debt markets up to any amount but only in the face of a steeply-rising endogenous country risk premium. Market debt carries an interest rate of $9.5 \%$ in the initial steady state but in our central simulations this rises by approximately 100 basis points for every additional 10 percent of GDP increase in public debt. ${ }^{12}$ Crucially, market debt is assumed to take time to arrange so disburses with a one year lag which implies taxation and domestic debt adjust to cover the transitional financing gap. Public debt is brought back to its initial steady state through an error correction mechanism operating at the same adjustment speed as the re-build of official reserves.

\section{Insurance}

Finally, the government can purchase parametric insurance from an offshore provider; this is assumed to pay out contemporaneously with rebuild expenditures and is free of basis risk (the contract always pays out when a cyclone of a pre-defined intensity hits and never pays out when

\footnotetext{
${ }^{12}$ We experiment with a range of higher and lower risk premia; these are discussed in Section 4.
} 
no cyclone occurs). Specifically, the contract pays out $100 \%$ of the cost of rebuilding destroyed public capital following all and any hurricanes of a severity greater than a 1-in-10 year event (the 'attachment point', equivalent to a voluntary excess in private insurance) up to a maximum payout defined by the cost of public capital reconstruction following a 1-in-100 year event (the 'exhaustion point'). With insurance in place, countries are assumed to rely on domestic financing for rebuilding following damage from small-intensity cyclones (below the attachment point) and on market debt and/or other financing for the excess cost over the insurance payout for events above the exhaustion point. In the realm of disaster risk insurance, premia are typically defined as $p=E[L o s s]+0.125 * s . d[L o s s]$ where $p$ is the required premium, $E[$ Loss $]$ is the expected value of the loss that will be borne by the insurer, and $s . d[L o s s]$ is the standard deviation of these losses. From the distributions fitted to data for CCRIF hurricane damage described in Section 3.1, this generates an annual 'market' risk premium of approximately $1.3 \%$ of initial GDP. CCRIF itself reports lower premia of around $0.75 \%$ of GDP on the contracts it writes, presumably reflecting a mixture of risk pooling and/or direct subsidy from donors. For illustration, we also consider a third case where we assume donors finance a deep discount on the CCRIF premium, lowering the annual premium to $0.25 \%$ of initial GDP.

Finally, we examine the case where insurance is bundled with technical support that allows an accelerated public sector rebuild rate, under which public investment increases by a maximum of $4 \%$ of initial GDP per annum, double the baseline rate. It would be straightforward to extend the model to relax any and all of these assumptions to allow for the sort of basis risk that characterizes parametric insurance contracts, for payouts not to be synchronized with expenditures, and for insurance coverage to be incomplete.

\subsection{Caveats and limitations}

Our approach, whilst tractable and well-designed to evaluate the characteristics of alternative policy responses to specific shocks, does have some drawbacks. The most obvious is that, in practice, while the underlying risk for a single year is resolved at the end of that year, the same distribution of risk is faced in the following and subsequent years, given the reasonable assumption that these sequential risks are independent. Hence, if the country is unlucky enough to be hit by a 1-in-500 event in year 1, it still faces a 1-in-500 risk of being hit by such an event in year 2 , and so on. To keep the simulations tractable, however, we draw on the tradition of impulse-response analysis and assume that the economy is exposed to the chosen risk distribution in the first year, but not in subsequent years. Hence, in our analysis, either the country escapes disaster, and continues to follow the calibrated balanced growth path, or it suffers an initial shock of a particular magnitude, in which case it implements some response strategy. In either case, there are no subsequent shocks to handle. ${ }^{13}$ In principle within this framework, we could

\footnotetext{
${ }^{13}$ To mix metaphors, either the country manages to dodge the bullet completely or is affected but believes that lightning never strikes twice.
} 
modify the initial 'impulse' to allow for the economy to be assaulted by mutliple sequential events - mutliple shocks across any arbitrary span of time and magnitude - and then explore the properties of response strategies in the face of these complex impulses. Evidently, this is a feasible approach but with multiple potential response strategies and a complex array of impulses, it clearly multiplies the potential experimental space far beyond what can readily be analysed.

The natural alternative approach to reflecting the reality that countries confront a stochastic disaster-risk future (in which economic agents' resource allocation decisions are conditioned on this stochastic environment) is to explicitly model economic outcomes by drawing repeated samples from the underlying risk distribution (see for example, Gourio (2012) and FernandezVillaverde and Levintal (2019)). The challenges with this approach are two-fold. First, because this latter class of model is more computationally demanding, it is correspondingly harder to analyse anything other than relatively simple policy response rules: for example, the range of hybrid response packages explored in this paper are likely to be very difficult to examine. Second, even within this class of model, an understanding of the mechanisms at play is typically facilitated by falling back on single-disaster impulse-response analysis. In ongoing companion work, we are exploring how to productively combine the insights from these two modelling traditions.

\section{Simulation Results and Welfare Analysis}

\subsection{Simulation runs}

We simulate the model under a sequence of single natural disasters ranging from a 1-in-10 year intensity up to a 1-in-750 year event and systematically vary the public investment and financing choices at each disaster intensity. To evaluate these choices, we must first define the relevant counterfactual. A simple 'no-disaster' scenario is unappealing since it implies a wholly different and unrealistic meta-environment for the analysis, but equally a counterfactual in which the authorities treat the natural disaster in a wholly fatalistic manner and simply seek to stabilize the economy at whatever level of public capital that remains undamaged post-hurricane, is also unattractive. A more plausible counterfactual, and the one used here, is a 'do nothing'strategy. Here, government holds its fiscal instruments, including gross public infrastructure investment, at their pre-disaster level: by doing so public capital returns slowly to its original level following a natural disaster but without any purposive change in fiscal direction by the authorities. The mechanism is simple: in the initial steady state, net investment (relative to the growth trend) is zero which means gross public investment exactly equals depreciation (plus trend growth). Once the hurricane has destroyed some portion of public capital, this 'do nothing' level of gross public investment now translates into positive net investment (because, with a lower public capital stock, the depreciation requirement has fallen). This positive net investment then finances a 
(slow) rebuild of the capital stock; net investment tapers to zero as the public capital approaches its pre-disaster steady-state trend value. It is this recovery path that defines our counterfactual. ${ }^{14}$

Table 3 describes this counterfactual plus a set of eleven substantive policy experiments that frame the central analysis of the paper. These do not, of course, constitute an exhaustive list of all possible responses, but they do span the range of ex post policy responses adopted by countries facing natural disasters (see the discussions in Bevan and Cook (2015) and Clarke et al (2016)). The policy experiments are divided across the three clusters discussed earlier, starting with four domestic financing packages. The second group substitutes external debt financing for elements of domestic financing, while the final cluster examines the role of market-based insurance. Within each cluster we explore a small number of significant variations. There are clearly many permutations that are not considered here, including both single-instrument financing strategies or alternative blended strategies, although an extensive exploration of alternative response policy combinations not reported here suggests the set we analyze here captures the relevant insights.

For each run, the model is simulated under each of eight draws from the distribution of hurricane intensities (no shock; 1-in-10; 1-in-25; 1-in-50; 1-in-100; 1-in-250; 1-in-500; and 1-in-750 year shocks). ${ }^{15}$ The path for private consumption and employment (for both household types) is used to define aggregate welfare for each draw from the shock distribution. These are then weighted by the probability weight for each shock, as described in Table 2 , to give the expected utility of consumption for each strategy. This is our summary welfare measure for each financing scenario which is then compared with the 'do nothing' scenario.

$$
<^{* *} \text { Table } 3 \text { here }^{* *}>
$$

\subsection{Impulse-response analysis}

We start by illustrating the macroeconomic dynamics of the model economy under different policy responses. To do so we focus on the impulse-response plots for a large and damaging 1-in-100 year tropical cyclone, given different policy responses drawn from the set outlined in Table $3 .{ }^{16}$ Figures $3-5$ illustrate three policy variations, starting in Figure 3 with the case of a domestically-financed reconstruction program, where we vary the authorities' capacity to access short-term domestic debt financing. ${ }^{17}$

The first panel shows the effect of the natural disaster (at $t=1$ ) on all three components of the aggregate capital stock and plots the recovery profiles for public capital, which is determined

\footnotetext{
${ }^{14}$ It is important to note that this is not a lower bound on the potential government response; a reduction in gross investment is also consistent with recovery, provided that net investment increases

${ }^{15}$ For each run, the model computes a 1000 period consumption path.

${ }^{16}$ In each case, we consider the case where the relatively scarce component of public capital bears the entire brunt of the public losses wreaked by the hurricane, where the elasticity of substitution between public capital components is low, and where there is a threshold in public capital (see Table 1, row 4).

${ }^{17}$ In the long-run, and in all cases, domestic debt reverts to its initial share of GDP, relative to trend. The variations considered here allow for greater or lesser short-run domestic borrowing but eventually the debt-to-GDP ratio must revert.
} 
by policy choice as described in Table 3, and the endogenous response of private capital. The complementarity between public and private capital is clear, with the latter recovering strongly only when the public capital stock is rebuilt. Under the domestic financing strategy, the first tranche of reconstruction financing comes from the drawdown of official reserves. Once these have been fully exhausted, which occurs after one full year (at the end of $t=2$ ), the incipient fiscal deficit is closed by a combination of increased consumption tax and domestic debt, depending on the domestic borrowing capacity. When domestic borrowing is constrained in the short-run (the dotted lines in Figure 3), domestic tax rates are required to rise very sharply, from 20 percent to well over 25 percent, exacerbating the recession in consumption (from $t=5$ to $t=10$ ). Greater reliance on short-term domestic borrowing (the solid line in Figure 3) smooths the tax rate and marginally softens the recession in consumption in the short-run but at the cost of higher taxation and lower consumption in the long run as the debt stock is slowly returned to its long run target.

\section{$<* *$ Figures 3,4 and 5 here ${ }^{* *}>$}

Figures 4 and 5 illustrate two variations on the same theme, in each case maintaining the assumption that the authorities can raise short-term domestic borrowing (i.e. the comparison is with 'solid line' case in Figure 3). Figure 4 makes the obvious point that external debt financing substitutes for domestic tax and debt financing in the short run, ameliorating the squeeze on consumption, and facilitating a slightly more rapid recovery in output. As external debt is repaid over the medium term domestic taxes are marginally higher and consumption marginally lower compared to the pure domestic financing case. Although not reported here, the case where the terms of external borrowing worsen - so that the country risk premium increases or the repayment terms shorten - follows an expected path: the short-run benefits of external debt financing are quickly extinguished by the additional burden of carrying expensive external debt into the future (See also Section 4.3).

Finally, Figure 5 highlights the counter-productive effects of budget reallocations that seek to finance reconstruction by paring back O\&M expenditures on the surviving (and new) public capital stocks. Lower O\&M expenditures not only depress the recovery in the effective public capital stock but, by slowing the reconstruction of private capital, attenuate the economic recovery while at the same time requiring a higher tax rate to finance reconstruction.

These trajectories give a sense of the underlying mechanisms at work in the model. The actual patterns will, of course, vary across the range of financing instruments and the intensity of the shock. In the next section, in order to examine the properties of alternative strategies across the full risk distribution, we summarize the data in a slightly different manner. 


\subsection{Comparative welfare analysis}

Tropical cyclones are always damaging to welfare. Short of receiving (instantaneously) external grant finance that meets the full cost of (both public and private) reconstruction plus an equivalent variation consumption transfer to restore consumption to its no-shock equilibrium path, all the scenarios considered here are associated with reduced welfare. Hence our analysis is focused on the comparative gains or losses of alternative stratagems for reconstruction of the public capital stock. Figure 6 illustrates the absolute welfare cost of cyclones of varying intensity. These are computed for the baseline 'do nothing' run relative to welfare in the absence of any cyclone (or risk of such). On this metric, the representative small Caribbean island welfare may be reduced in expectation by approximately 2.6 percent, these welfare costs may be much more substantial in the face of high-damage cyclone events. Against this background, even the most favourable policy responses improve welfare by only around $7.5 \%$ in expectation relative to the 'do-nothing' strategy.

Table 4 summarizes how this expected welfare outcome is moderated under different financing strategies across events of differing intensities. Figures 7 and 8 display the same evidence: Figure 7 ranks policy responses in terms of expected welfare across all risks, relative to the 'do nothing' counterfactual, while Figure 8 decomposes the relative welfare costs or gains of each strategy by the intensity of each natural disaster .

\section{$<* *$ Table $4^{* *}>$ \\ $<* *$ Figures 6,7 and $8^{* *}>$}

Three main results stand out. First, in the absence of donor grants, a strategy of purposive domestic tax-financing remains the best method of rebuilding public capital, and is generally preferable to external-debt or insurance-based strategies, and this is more so if at the margin the additional tax revenues are generated by consumption taxes which are the least distortionary tax instrument in this model. But there are caveats, the principal one being that the dominant role for domestic financing in these simulations reflects a structure in which tax distortions are relatively small and the tax rate can be raised quickly and substantially if required. Clearly, domestic financing options become less favourable if taxation is more distortionary - as can be seen from the comparison of the consumption-based and output-based tax financing strategies (cases A and B). More importantly, however, political economy constraints, not captured in the model as currently presented, may well render infeasible the large and rapid increases in taxes required here when larger disasters strike, meaning alternative financing mechanisms are required. The most obvious case is presented in scenario $\mathrm{C}$ where the authorities seek to finance reconstruction by diverting recurrent expenditure away from meeting essential operations and maintenance expenditures on the existing capital stock. By reducing the effectiveness of the established (and re-built) public capital this reduces the returns to private capital, lowering 
private investment and slowing the post-cyclone recovery. In the experiment shown here, the budget reallocation is modest. O\&M expenditures are cut by only 10 percent of their efficient levels and for a maximum of two years post-disaster. Even in this case the outcome is marginally worse in expectation than a 'do nothing' approach: if reallocation plays a more significant role, the damage is likely to be serious.

Second, if an increase in taxation is infeasible, either because of political resistance to raising taxation in times of crisis or because this is administratively impractical (see Bevan and Cook, 2015), external debt financing is a feasible alternative when the country risk premium is low, but quickly becomes very unattractive if the supply curve for external debt rises sharply, which would be the case if the country's credit rating was weak - either because of its vulnerability to natural disasters or for other structural reasons. In this respect, the results presented for Case $\mathrm{F}$ in Table 4 and Figures 7 and 8 are not entirely credible: it is highly unlikely in a world where the country risk premium is large that any conventional market lending would be forthcoming following extreme disaster events.

Third, unless the risk premium is heavily subsidized policy responses built around marketbased insurance are also relatively unattractive, but for different reasons. Whereas the burden of strategies built around market debt are rendered infeasible ex post, insurance-based programs pay off when big shocks hit. What makes parametric insurance contracts prohibitively expensive is the high carrying costs. Two possible modifications start to bring insurance contracts into play. The first is obviously the premium and the second is if insurance contracts are bundled with technical assistance or other logistic support that allows for a more rapid pace of reconstruction. Experiment J shows the effect of subsidy that reduces by one third the average CCRIF premium (which itself is heavily discounted on market rates) while experiment $\mathrm{K}$ assume that insurance is still purchased at the CCRIF rate but that technical assistance and logistics support allow the public investment rate to rise by 4 percentage points of GDP per annum during the reconstruction phase as opposed to the 2 percentage points assumed elsewhere.

It is relatively straightforward to use these insights to construct a range of more complex financing strategies by combining the elements presented here. Perhaps the most obvious in the context of Table 4 is a 'tax-and-insurance' programme that relies of reserve drawdowns and available tax capacity to self-insure against relatively high frequency events, say up to the 1-in100 level, and to supplement this with external insurance only for low-frequency, high-damage events.

\section{Summary and Conclusions}

Quite apart from the immediate and ongoing humanitarian issues they pose, natural disasters have widespread economic impacts, not least to capital assets. These impacts, in turn, pose a variety of challenges to public policy in general and to choices over the public finances in 
particular. This paper shows how a dynamic general equilibrium model may help to throw some light on these choices.The model is well-adapted to examining quite complicated events, including damage to public and private capital, as well as other mechanisms leading to temporary losses of current output. It is capable of comparing varied financing packages, including domestic taxation, domestic borrowing, external concessional and non-concessional borrowing, external grants, and public expenditure reallocation, with or without accompanying insurance contracts, and it can do so for a range of blended strategies. The key contribution of the analysis is to highlight both the centrality for private productivity and welfare of the speed of reconstruction of the public capital stock but also how different financing mechanism can militate against effective reconstruction. The results highlight most clearly the counter-productivity of budget reallocations that seek to raid operations and maintenance budgets. Such strategies are often seen as ways of avoiding the politically difficult task of making purposive announced tax increases, but they can be extremely damaging. But if reallocation is to be avoided and increased taxation is infeasible, whether debt financing or insurance contracts should be taken out is quite dependent on a number of factors, including the country's (post-disaster) creditworthiness, and the ability to benefit from risk-pooling mechanisms and/or donor support to lower the carrying cost of still-expensive parametric insurance contracts.

We conclude by noting one key strength of the approach adopted here and three areas where further work is required. The strength is to emphasise that it is possible, within a quite simple model, to explore a very rich set of alternative natural disaster scenarios and possible policy responses that go beyond those considered here. In terms of areas where more work is required, the first arises as a direct consequence of this strength; there are too many options to consider in any very general context. Hence full utilization of this approach requires a detailed specification of country-specific circumstances to be embedded in the analysis. The second area for further work, as noted above, is that the impulse-response framework deployed here to examine responses to single discrete events is not easily modified to reflect a world in which countries in disasterprone regions live in a stochastic environment characterized by multiple and repeated natural disasters. The third and related issue concerns the way we characterize private investment behaviour in environments in such disaster-prone environments. Our model, consistent with similar work in this area, adopts a dynamic macroeconomic closure in which private savings and investment are brought into line through the interaction of a Tobin $q$ investment function and the household Euler equation. In this framework, conditional on external financing, the real interest rate adjusts to ensure that household inter-temporal consumption adjusts to deliver the volume of savings required to finance desired investment. While this may be a reasonable structure in 'normal' time, but in uncertain environments, where households face the prospect of repeated natural disasters, this structure may over-simplify investment behavour. It may be more plausible to characterise investors' re-building strategies following natural disasters 
according to bounded, 'rule-of-thumb' investment strategies. The exploration of rule-of-thumb investment strategies in the context of repeated stochastic shocks is the subject of future work. 


\section{References}

- Adam, C. and D. Bevan, (2014), "Public Investment, Public Finance and Growth: the Impact of Distortionary Taxation, Recurrent Costs and Incomplete Appropriability", IMF Working Paper WP 14/73.

- Ahmad, E.and N.Stern (1984) "The Theory of Reform and Indian Indirect Taxes", Journal of Public Economics 25 (3): 259-298.

- Auriol, E. and M. Warlters (2012) "The Marginal Cost of Public Funds and Tax Reform in Africa", Journal of Development Economics 97(1): 58-72.

- Berg, A., E.Buffie, C.Pattillo, R.Portillo, A.Presbitero and L-F. Zanna (2019), "Some Misconceptions about public investment efficiency and growth" Economica 86: 409-430.

- Bevan, D. and C.Adam (2016) "Financing the Reconstruction of Public Capital after a Natural Disaster" World Bank Policy Research Working Paper, WPS 7718.

- Bevan, D. and S. Cook, (2015), "Public Expenditure Following Disasters", World Bank Policy Research Working Paper, WPS 7355.

- Browning, E. (1976) "The Marginal Cost of Public Funds", Journal of Political Economy 84 (2): 283-298.

- Buffie, E., A. Berg, C. Pattillo, R. Portillo and L-F. Zanna, (2012), "Public Investment, Growth, and Debt Sustainability: Putting Together the Pieces.", IMF Working Paper WP12/144.

- Clarke, D., O. Mahul, R. Poulter and T. L. Teh (2016) "Evaluation Sovereign Disaster Risk Finance Strategies: A Framework", World Bank Policy Research Working Paper 7721.

- Fernandez-Villaverde, J. and O.Levintal (2019) "Solution methods for models with rare disasters" Quantitative Economics 9: 903-944.

- Gourio, F. (2012) "Disaster Risk and Business Cycles" American Economic Review 102 (2): 2734-2766.

- Heller, P. S. (1991) "Operations and Maintenance", in IMF Public Expenditure Handbook Washington DC: IMF.

- IMF, (2014), Jamaica Article IV Report, Country Report 14/169.

- Melina, G., S.Yang and L-F Zanna (2016) "Debt sustainability, public investment, and natural resources in developing countries: The DIGNAR model" Economic Modelling 52: 630-649. 
- Noy,I., A.Kusuma and C.Nguyen (2017) "Insuring disasters: a survey of the economics of insurance programs for earthquakes and droughts" School of Economics and Finance Working Paper 11/2017 Victoria Business School, New Zealand.

- Statistical Institute of Jamaica, (2015), National Accounts, 2013-14.

- World Bank (2016) "Jamaica: Hurricanes and Earthquakes Risk Profile" World Bank: Country Disaster Risk Profiles (http://documents.worldbank.org/curated/en/859361493272944514/pdf/1 WP-PUBLIC-drp-jamaica.pdf)

- World Bank (2018) Advancing Disaster Risk Financing in Jamaica World Bank, Social, Urban, Rural and Resilience Global Practice: Latin American and the Caribbean Unit

- Zanna, L-F., E. Buffie, R. Portillo, A. Berg and C. Pattillo (2019) "Borrowing for Growth: Big Pushes and Debt Sustainability in Low-Income Countries" World Bank Economic Review 33(3): 661-689. 


\section{Appendix I: The Model}

The model describes a two-sector small open economy producing a traded good $q_{x}$ and a nontraded good $q_{n}$ from private capital, labor, and government-supplied infrastructure. Households consume domestically-produced goods along with imported consumption goods $c_{m}$. Capital goods (machines) $m_{m}$, are also imported and combined with the non-traded good to produce private capital and infrastructure (public capital). All quantity variables except labor are detrended by $(1+g)^{t}$, where $g$ is the exogenous long-run growth rate of real GDP and $t$ is the time index. The model abstracts from money and all nominal rigidities, but includes taxation and a lump-sum transfer from government to private agents, as well as grants, remittances and a variety of forms of public and private debt.

\section{Firms}

In the two productive sectors $j=n, x$, sectoral output, $q_{j}$ is produced by a Cobb-Douglas combination of labour, private capital, and public capital:

$$
q_{j, t}=a_{j, t}\left(z_{t-1}-\bar{z}\right)^{\psi_{j}}\left(k_{j, t-1}\right)^{\alpha_{j}}\left(L_{j, t}\right)^{1-\alpha_{j}} .
$$

where the $a_{j}$ are sector-specific productivities, labor is given as $L_{j, t}$, sectoral private capital $k_{j, t-1}$, and 'effective' government infrastructure $z_{t-1}^{e}$, which contributes to output only when it exceeds a minimum threshold, $\bar{z}$. There are constant returns to private factors, with capital shares $\alpha_{j}$, but increasing returns in the presence of public infrastructure as measured by $\psi_{j}$.

Public and private capital is built by combining imported machines and a non-traded input (e.g., construction) in fixed proportions, determined by $a_{k}$ and $a_{z}$ respectively. The supply prices of private capital and infrastructure are thus:

$$
\begin{aligned}
& P_{k, t}=\left(1-a_{k}\right) P_{m, t}+a_{k} P_{n, t} \\
& P_{z, t}=\left(1-a_{z}\right) P_{m, t}+a_{z} P_{n, t}
\end{aligned}
$$

where $P_{n}$ is the price of the non-traded good and $P_{m}$ the price of imported machinery.

Public capital is a composite consisting of two components, $z_{1}$ and $z_{2}$ ('bridges and roads'), which are combined using a CES aggregator to form the composite $z$ :

$$
z^{e}=\left(\gamma^{(1 / \epsilon)} z_{1}^{e(1-1 / \epsilon)}+(1-\gamma)^{(1 / \epsilon)} z_{2}^{e(1-1 / \epsilon)}\right)^{1 /(1-1 / \epsilon)}
$$

where $\epsilon$ is the elasticity of substitution between the two components. The effectiveness of public capital depends on the scale of recurrent operations expenditures. See equation (5.22) below. 
Competitive profit-maximizing firms equate the (private) marginal value product of labour to its factor price,

$$
P_{j, t}\left(1-\alpha_{j}\right) \frac{q_{j, t}}{L_{j, t}}=\left(1+\theta_{w, t}\right) w_{t}
$$

for $j=x, n$ where $w_{t}$ is the net of tax wage, and $\theta_{w, t}$ is the tax of labour. Labor is intersectorally mobile so that $w_{t}$ is equalized across the two sectors. Likewise the marginal product of private capital is equated to the tax-adjusted rental rate. With the CES composite, the first order condition for capital which takes the form:

$$
P_{j} \alpha_{j} \frac{q_{j, t}}{k_{j, t-1}}=\left(1+\theta_{k, t}\right) r_{j, t} .
$$

where $r_{j}$ is the gross rental earned by capital in sector $j$ and $\theta_{j}$ the tax rate on (sector-specific) capital income. Capital is sector-specific but at equilibrium the allocation of $k_{x}$ and $k_{n}$ ensures net-of-tax gross rental rates in each sector are equal to the opportunity cost of capital as shown in (5.16) below. Taxes on factors drive wedges between private and social values.

\section{Households}

There are two types of private households, savers and non-savers, distinguished by the superscripts $i=s, h$ respectively. The ratio of non-saver to saver households is given by $a$. Households are infinitely-lived with utility, for both savers and non-savers, defined by the following function:

$$
U^{i}=\sum_{t=0}^{\infty} \beta^{t}\left[\frac{\left(c_{t}^{i}\right)^{1-1 / \tau^{i}}}{1-1 / \tau^{i}}-\kappa^{i} \frac{\left(L_{t}^{i}\right)^{1+1 / \iota^{i}}}{1+1 / \iota^{i}}\right]
$$

where $\beta$ is the discount factor; $\tau$ is the inter-temporal elasticity of substitution in consumption and $\iota$ the Frisch elasticity of labor supply. Aggregate consumption, $c_{t}$, is defined as a constant elasticity of substitution (CES) aggregate defined over the domestic traded good $c_{x, t}^{i}$, the foreign traded good $c_{m, t}^{i}$, and the domestic non-traded good $c_{n, t}^{i}$ for $i=s, h$, thus:

$$
c_{t}^{i}=\left[\rho_{x}^{\frac{1}{\epsilon}}\left(c_{x, t}^{i}\right)^{\frac{\epsilon-1}{\epsilon}}+\rho_{m}^{\frac{1}{\epsilon}}\left(c_{m, t}^{i}\right)^{\frac{\epsilon-1}{\epsilon}}+\rho_{n}^{\frac{1}{\epsilon}}\left(c_{n, t}^{i}\right)^{\frac{\epsilon-1}{\epsilon}}\right]^{\frac{\epsilon}{\epsilon-1}}
$$

for $i=s, h$ where $\rho_{x}, \rho_{m}$, and $\rho_{n}$ are CES distribution parameters with $\rho_{x}+\rho_{m}+\rho_{n}=1$, and $\epsilon$ is the elasticity of substitution between the commodities. These parameters are common across the two households. The true consumer price index associated with the (common) consumption basket is:

$$
P c_{t}=\left[\rho_{x} P_{c x, t}^{1-\epsilon}+\rho_{m} P_{c m, t}^{1-\epsilon}+\rho_{n} P_{c n, t}^{1-\epsilon}\right]^{\frac{1}{1-\epsilon}}
$$


with demand functions for each good:

$$
c_{l, t}^{i}=\rho_{l}\left(\frac{P_{c l, t}}{P c_{t}}\right)^{-\epsilon} c_{t}^{i}
$$

for $l=x, m, n$ and $i=s, h$. Consumer prices are defined as

$$
P_{c l, t}=\left(1+h_{l}\right) P_{l, t}
$$

where $h_{l}$ denotes the consumption tax rate on commodity $c_{l}$.

The saving household spends on final consumption, $c_{t}^{s}$, invests quantities $i_{x}$ and $i_{n}$ in private capital, with adjustment costs $A C_{x}$ and $A C_{n}$ defined in (5.17) below, that depreciates at the rate $\delta$, and buys domestic bonds $b_{t}^{s}$. Domestic bonds, which cannot be held by foreigners, pay a real interest rate $r$. This household maximizes its utility for $i=s$ subject to the budget constraint:

$$
\begin{gathered}
\triangle b_{t}^{s}=r_{t-1} b_{t-1}^{s}+\sum_{j} r_{j, t} k_{j, t-1}^{s}+\frac{1}{1+a}\left[w_{t}\left(L_{n, t}+L_{x, t}\right)+T_{t}+R_{t}\right] \\
-P_{k, t}\left(i_{x, t}+A C_{x, t}+i_{n, t}+A C_{n, t}\right)-P c_{t} c_{t}^{s}
\end{gathered}
$$

where $\triangle b_{t}^{s}=b_{t}^{s}-b_{t-1}^{s}$ and the equations of motion for capital in the tradable and non-tradable sectors respectively are

$$
(1+g) k_{j, t}^{s}=i_{j, t}^{s}+(1-\delta) k_{j, t-1}^{s}
$$

for $j=x, n$. The household receives a flow of remittances from overseas, $R_{t}$ and transfers from government, $T_{t}$. The first order conditions describing the solution to the saving household's optimization problem are:

$$
\begin{gathered}
\frac{c_{t+1}^{s}}{c_{t}^{s}}=\left(\beta \frac{1+r_{t}}{1+g} \frac{P c_{t}}{P c_{t+1}}\right)^{\tau^{s}} \\
L_{t}^{s}=\left[\left(c_{t}^{s}\right)^{-1 / \tau^{s}}\left(\frac{1}{\kappa^{s}}\right) \frac{w_{t}}{P c_{t}}\right]^{\iota^{s}} \\
\frac{r_{j, t+1}}{P_{k, t+1}}+1-\delta=\left(1+r_{t}\right) \frac{P_{k, t}}{P_{k, t+1}}
\end{gathered}
$$

The first condition is an Euler equation in which the slope of the consumption path depends on the bond interest rate adjusted for trend growth $(g)$ and on changes in the (tax inclusive) consumer price index. The second defines the the labor supply of the saving household, and the final condition establishes the arbitrage conditions, requiring the net rate of return on capital in each sector $j=x, n$ to equal the interest rate. 
Private investors face adjustment costs of the form

$$
A C_{j, t}=\left(\frac{\nu_{j}}{2}\right) k_{j, t-1}\left[\left(\frac{i_{j, t}}{k_{j, t-1}}\right)-\delta_{j}-g\right]^{2}
$$

The non-saving household maximizes the same utility function as that of savers, so that the labor supply by this household is analogous and is given by

$$
L_{t}^{h}=\left[\left(c_{t}^{h}\right)^{-1 / \tau^{h}}\left(\frac{1}{\kappa^{h}}\right) \frac{w_{t}}{P c_{t}}\right]^{\iota^{h}}
$$

With no access to capital markets, non-saving households have no claims on either fixed capital or on bonds so that their income consists of wages, remittances, transfers and their share of the labor and consumption taxes not remitted to government less their share of user fees for the use of public capital. The consumption of non-saving households is therefore defined directly from their budget constraint :

$$
P c_{t} c_{t}^{h}=\frac{a}{1+a}\left[w_{t}\left(L_{n, t}+L_{x, t}\right)+T_{t}+R_{t}\right]
$$

Households are aggregated over $i=s, h$, so that $x_{t}=x_{t}^{s}+x_{t}^{h}$ for $x_{t}=c_{l, t}, L_{t}, b_{t}, i_{j, t}, k_{j, t}$, and the sub-indices $l=x, n, m$ and $j=x, n$. By definition, for non-saving households $b_{t}^{h}=i_{j, t}^{h}=$ $k_{j, t}^{h}=0$ for $j=x, n$.

\section{Government}

Government provides public infrastructure and makes transfers to both households. To finance these activities it raises taxes on domestic economic activity, borrows from domestic and external creditors and receives concessional aid and grants from development partners. Government may also levy user charges on households for the use of public capital. In a disaster-prone environment, the government may also accumulate precautionary official reserves and contract disaster risk insurance.

To allow for inefficiencies in the operation of public capital, we distinguish between two different notions of public capital: installed capital $(z)$ and effective (or effectively productive) capital $\left(z^{e}\right) .{ }^{18}$ Public investment $i_{z}$ produces additional units of installed infrastructure $z$ according to: ${ }^{19}$

$$
(1+g) z_{t}=(1-\delta) z_{t-1}+i_{z, t}
$$

\footnotetext{
${ }^{18} \mathrm{It}$ is straightforward to allow for corruption and/or other inefficiencies to drive a wedge between the investment in public capital and the quantum eventually installed. Given the focus of this paper we abstract from this potential distortion but see Berg et al (2019).

${ }^{19}$ In the simulations reported below, public investment can be changed without adjustment costs. It is a simple matter to include these by allowing adjustment costs of the form $\Pi_{t}=$ $\left(\left(i_{z, t}-\overline{i_{z}}\right) \cdot\left(1+\frac{i_{z, t}}{z_{t-1}}-\delta-g\right)^{\phi}+\overline{i_{z}}\right) / i_{z, t}$ which are increasing in the notional investment rate rate.
} 
Operations and maintenance expenditures affect public capital through two channels in the model. On the one hand, deficient maintenance expenditure leads to an increase in the rate at which the public capital stock depreciates through time

$$
\delta_{z}^{i}=\delta_{z}\left[1+\left(1-\gamma_{m}\right) \beta_{\delta}\right]
$$

where $0<\gamma_{m} \leq 1$ is the ratio of actual to efficient maintenance expenditure and $\beta_{\delta} \geq 0$ is a measure of excess depreciation. Thus the rate of depreciation is bounded between $\delta_{z}$ when maintenance is at its efficient level and $\delta_{z}\left(1+\beta_{\delta}\right)$ when maintenance is neglected entirely. On the other, deficient operations expenditure reduces the flow of output produced by the current stock of public capital, such that, effective capital is defined as

$$
z^{e}=\gamma_{p} z
$$

where $0<\gamma_{p} \leq 1$ is the ratio of actual to efficient operations expenditure. For simplicity, these operations and maintenance requirements are treated as being kinked at the efficient level; while there is an immediate loss involved when either $\gamma$ is allowed to fall below 1 , there is no corresponding gain if either is set greater than 1 . Such excess expenditure would just be wasted. Both effects can be temporary so that a return to 'full' maintenance and operations expenditures restores the (technical minimum) depreciation rate and the full flow of output respectively. ${ }^{20}$

Delivery of operations and maintenance expenditures require traded and non traded inputs. The composite price of $\mathrm{O} \& \mathrm{M}$ is $P_{o m, t}=\left(1-a_{n}\right) P_{x, t}+a_{n} P_{n, t}$ where $a_{n}$ is the non-tradable share in absorption, so that an increase in the level of O\&M as a share of total absorption leaves the initial price vectors undisturbed. The quantities of this composite good are then defined respectively as $q_{p, t} z_{t-1}$ and $q_{m, t} z_{t-1}$ where $q_{p, t}=\gamma_{p, t} \bar{q}_{p}$ and $q_{m, t}=\gamma_{m, t} \bar{q}_{m}$ with $\overline{q_{p}}$ and $\overline{q_{m}}$ measures of 'efficient' O\&M goods expenditures per unit of installed capital.

Adding in depreciation and debt-financing costs the full cost of public investment is given as

$$
\left[P_{o m, t}\left(q_{p, t}+q_{m, t}\right)+\left(\delta_{z, t}^{i}+r_{t}^{g}\right) P_{z, t}\right] z_{t-1}^{i}
$$

The first two terms are the recurrent cash costs of operations and maintenance; the third and fourth terms correspond to the depreciation and financing costs per unit of installed capital, where $r_{t}^{g}$ is the marginal cost of government (non-concessional) borrowing, recognizing that a unit of installed capital costs $P_{z}$ to replace.

The period budget constraint is given by

\footnotetext{
${ }^{20}$ This is a simplifying assumption: in practice, the capital stock may be so degraded as a result of deficient maintenance expenditures that it is simply not possible to restore it to 'full' efficiency without rebuilding afresh.
} 


$$
\begin{gathered}
\Delta b_{t}+\Delta d_{c, t}+\Delta d_{t}-\Delta n i r_{t}=\frac{r_{t-1}-g}{1+g} b_{t-1}+\frac{r_{d, t-1}-g}{1+g} d_{t-1}+\frac{r_{d c, t-1}-g}{1+g} d_{c, t-1}+P_{z, t} i_{z, t} \\
+P_{o m, t}\left(q_{m . t}+q_{p, t}\right) z_{t-1}+T_{t}-\frac{r_{f}-g}{1+g} n i r_{t-1} \\
-\sum_{j} \theta_{j, t} r_{j, t} k_{j, t-1}^{s}-\theta_{w, t} w_{t}\left(L_{n, t}+L_{x, t}\right)-\sum_{l} h_{l, t} P_{l, t} c_{l t}+\phi_{t}-H_{t}
\end{gathered}
$$

for $j=x, n$ and $l=x, m, n$. The government spends on debt service, infrastructure investment, associated operations and maintenance, and transfers to the private sector. It earns interest on its net international reserves, collects tax revenue from consumption taxes and from taxes on capital and labor. If government has taken out disaster risk insurance it pays a premium, $\phi$, and receives payouts $H$ conditional on a hurricane event (See Section 3 for a description of the insurance contract). When revenues fall short of expenditures, the resulting deficit is financed through domestic borrowing $\Delta b_{t}=b_{t}-b_{t-1}$, external concessional borrowing $\Delta d_{t}=d_{t}-d_{t-1}$, external commercial borrowing $\Delta d_{c, t}=d_{c, t}-d_{c, t-1}$, or by drawing down net international reserves $\Delta n i r_{t}=n i r_{t}-n i r_{t-1}$. The (constant) world risk free rate, payable on reserves, is $r_{f}$; the interest rate on concessional loans is assumed to be constant $r_{d, t}=r_{d}$, while the interest rate on external commercial debt incorporates a risk premium that depends on the deviations of the external public debt to GDP ratio $e d_{t}=\frac{d_{t}+d_{c, t}-n i r_{t}}{y_{t}}$ from its (initial) steady state value where $y_{t}=P_{x, t} q_{x, t}+P_{n . t} q_{n, t}$ is GDP. That is,

$$
r_{d c, t}=r_{f}+v_{g} e^{\eta_{g}\left(e d_{t}-\bar{e} d\right)}
$$

If $v_{g}>0$ and $\eta_{g}=0$, this specification provides for an exogenous risk premium that does not depend on the level of public debt; if both are positive, the premium is increasing in the external debt to GDP ratio.

Government in this model has a large array of fiscal instruments. As described in Sections 4 and 5 above we explore a range of purposive adjustment rules but in each case we allow domestic taxation and bonds to serve as the residual fiscal financing instruments that adjust to satisfy the fiscal balance according to the following rules:

$$
\begin{gathered}
h_{t}^{*}=h_{0}+\lambda\left(\frac{\Theta_{t}}{P_{x, t} c_{x, t}+P_{m . t} c_{m, t}+P_{n . t} c_{n, t}}\right) \\
h_{t}=h_{t-1}+\lambda_{h 1}\left(h_{t}^{*}-h_{t-1}\right)+\lambda_{h 2}\left(\frac{b_{t-1}-b^{*}}{y_{t}}\right)
\end{gathered}
$$

The starting point for this rule is the incipient 'fiscal gap' $\Theta_{t}$, which measures the fiscal balance at the pre-shock prevailing tax rates and debt levels. Conditional on this gap, $h_{t}^{*}$ defines the required adjustment to the consumption tax rate to close the gap, if taxation could adjust 
instantaneously. In practice, however, actual taxation, $h_{t}$,can adjust only gradually, as governed by $\lambda_{h 1}$, with the short-run gap being financed by domestic debt issue, $b_{t}$. A directly analogous set of rules apply for factor taxes, $\theta_{t}$

$$
\begin{gathered}
\theta_{t}^{*}=\theta_{0}+(1-\lambda)\left(\frac{\Theta_{t}}{r_{n} k_{t-1}^{n}+r_{x} k_{t-1}^{x}+w_{t}\left(L_{n, t}+L_{x, t}\right)}\right) \\
\theta_{t}=\theta_{t-1}+\lambda_{\theta 1}\left(h_{t}^{*}-h_{t-1}\right)+\lambda_{\theta 2}\left(\frac{b_{t-1}-b^{*}}{y_{t}}\right)
\end{gathered}
$$

where $\lambda$ determines the share of tax adjustment borne by consumption taxes, and $(1-\lambda)$ the share borne by factor taxes.

\section{Market-clearing conditions}

Flexible wages and prices ensure that demand continuously equals supply in the labor market:

$$
L_{x, t}+L_{n, t}=L_{t}^{h}+L_{t}^{s}
$$

Aggregating over both types of consumers, and taking into account private and public investment and O\&M expenditures, equilibrium in the non-tradable sector is:

$$
q_{n, t}=\rho_{n}\left(\frac{P_{n, t}}{P_{t}}\right)^{-\epsilon} c_{t}+a_{k}\left(i_{x, t}+A C_{x, t}+i_{n, t}+A C_{n, t}\right)+a_{z} i_{z, t}+a_{n}\left(q_{m, t}+q_{p, t}\right) z_{t}^{i}
$$

Finally, consolidating public and private sector budget constraints yields the accounting identity that growth in the country's net foreign debt equals the difference between national spending and national income:

$$
\begin{gathered}
\Delta d_{t}+\Delta d_{c, t}-\Delta n i r_{t}=\frac{r_{d}-g}{1+g} d_{t-1}+\frac{r_{d c, t-1}-g}{1+g} d_{c, t-1}-\frac{r_{f}-g}{1+g} n i r_{t-1}+P_{z, t} i_{z, t} \\
+P_{k, t}\left(i_{x, t}+A C_{x, t}+i_{n, t}+A C_{n, t}\right)+P_{o m, t}\left(q_{p, t}+q_{m, t}\right)+P_{t} c_{t}-P_{n, t} q_{n, t}-P_{x, t} q_{x, t}+\phi_{t}-H_{t}
\end{gathered}
$$




\section{Appendix II: Modeling the Probability Distribution of Disasters}

The observational data shown in Figure 1 are quite sparse, and constructed around a number of isolated observations from the presumed underlying distribution where, in a statistical sense, rare extreme events are under-sampled. These data consist of a set $i=1, n$ of points of damage at scale $d_{i}$ associated with probabilities $p_{i}$.

Our raw data consist of a set of 7 'observed' data points corresponding to positive events available to us from Figure 2 (these are 1-in-10, 1-in-25, 1-in-50, 1-in-100, 1-in-250, 1-in-500 and 1-in-750 year shocks). A natural starting point involves fitting to these positive damage points a simple negative exponential of the form:

$$
P(d)=(1-\theta) \lambda e^{-\lambda d}
$$

where $d$ is the extent of the loss, and $\theta$ is the size of the no-event mass point. If the negative exponential were a good fit, plotting the logarithm of the probabilities against the associated damage should lie close to a straight line. In fact, the data seem to lie roughly along two straight lines, with a sharp kink at around what would be the 1-in-15 year return. That suggests a piece-wise function consisting of the sum of two negative exponentials, both running from zero to infinity, i.e.

$$
P(d)=(1-\theta)\left\{a \lambda_{1} e^{-\lambda_{1} d}+(1-a) \lambda_{2} e^{-\lambda_{2} d}\right\}
$$

where $a$ is a distribution parameter to ensure that the aggregate probability of positive events continues to sum to $(1-\theta)$. This approach provides a good fit to the available data. ${ }^{21}$

However it makes more sense to replace these observed point values by values representing the area under the function for the range in which the observed values are centered. Thus, we create a new variable $g_{i}=\left(d_{i}+d_{i+1}\right) / 2, i=1, n-1$, supplemented by setting $g_{0}=0$ and $g_{n}=9999{ }^{22}$ These $g_{i}$ points partition the x-axis into slices that are centred on the original $d_{i}$ points. Integrating between successive $g_{i}$ points now yields the probability and the cumulative damage associated with each slice. Hence, we now compute the new values for the probability and cumulative damage:

$$
\begin{gathered}
P_{i}=\left(1-\theta_{0}\right) \int_{g_{i-1}}^{g_{i}}\left\{a \lambda_{1} e^{-\lambda_{1} d}+(1-a) \lambda_{2} e^{-\lambda_{2} d}\right\} d d \\
G_{i}=\left(1-\theta_{0}\right) \int_{g_{i-1}}^{g_{i}} d\left\{a \lambda_{10} e^{-\lambda_{10} d}+(1-a) \lambda_{20} e^{-\lambda_{20} d}\right\} d d
\end{gathered}
$$

\footnotetext{
${ }^{21}$ Details are available from the authors.

${ }^{22}$ Other choices could be made as to how to partition the 'x-axis' between adjacent points, but this half-and-half assumption seems simplest, and is probably fairly innocuous.
} 


$$
D_{i}=G_{i} / P_{i}
$$

The last step arises because the cumulative damage $G_{i}$ needs to be deflated with its associated probability to obtain the new point value for damage in that range, to obtain $D_{i}$. The sequence of modified point values along with associated probabilities are reported in Table 2. 


\section{Appendix Table I: Baseline Calibration Parameters}

\begin{tabular}{|c|c|c|}
\hline Parameters & Values [*] & Definition \\
\hline$a$ & 1.5 & Ratio of non-saving to saving households \\
\hline$\alpha_{x}, \alpha_{n}$ & $0.40,0.30$ & Capital share in $x$ and $n$ sectors \\
\hline$\psi_{x}, \psi_{n}$ & $0.20,0.20$ & Output elasticity with respect to infrastructure in $n$ and $x$ sectors \\
\hline$a_{k}, a_{z}, a_{o m}$ & $0.5,0.5,0.5$ & Non-tradable cost share in private capital, public capital and O\&M \\
\hline$\gamma$ & {$[0.4,0.6]$} & Share of $z_{1}$ in composite public capital \\
\hline$\varepsilon_{z}$ & {$[0.25,1000]$} & Elasticity of substitution between components of public capital \\
\hline$\rho_{x}, \rho_{n}, \rho_{m}$ & $0.20,0.40,0.40$ & Distribution parameters for $x, n$ and $m$ sectors \\
\hline$\varepsilon$ & 0.5 & Intra-temporal elasticity of substitution in consumption \\
\hline$\gamma_{p}^{*}, \gamma_{m}^{*}$ & $0.025,0.025$ & Efficient operations and maintenance expenditures per unit of public capital \\
\hline$\tau$ & 0.5 & Inter-temporal elasticity of substitution \\
\hline$\nu_{x}, \nu_{n}$ & $1.5385,1.5385$ & Private sector aadjustment cost parameter \\
\hline$\iota$ & 0.25 & Frisch elasticity of labour supply \\
\hline$\vartheta$ & 0.0591 & Pure subjective time preference rate [Discount factor $\beta=1 /(1+\vartheta)$ ] \\
\hline$\delta$ & 5.0 & Baseline depreciation rate (\% per annum) \\
\hline$\beta_{\delta}$ & 1.0 & Accelerated public capital depreciation parameter \\
\hline$\gamma_{p}, \gamma_{m}$ & $1.0,1.0$ & Baseline efficiency parameters for operations and maintenance expenditures \\
\hline$\lambda$ & {$[1.0,0.0]$} & Weight on consumption tax in (long-run) fiscal reaction function \\
\hline$\lambda_{h 1}$ & {$[0.95,0.75]$} & Autoregressive parameter on tax adjustment in short-run fiscal reaction function \\
\hline$\lambda_{h 2}$ & {$[0.10,0.25]$} & Autoregressive parameter on tax adjustment in short-run fiscal reaction function \\
\hline
\end{tabular}

* Values in parenthesis indicate experimental ranges. 


\begin{tabular}{ccl} 
Baseline values & Values & Definition \\
\hline$g$ & 1.5 & Exogeneous trend growth rate (\% p.a.) \\
$\bar{z}$ & {$[0,0.25]$} & Threshold in public capital \\
$h$ & 20 & Consumption tax rate (\% consumption) \\
$\theta_{w}$ & 0.10 & Wage tax (\% gross wages) \\
$\theta_{x}, \theta_{n}$ & 0.10 & Profit tax (\% of profits) \\
$\bar{l}, \bar{q}$ & $2.5,2.5$ & Efficient O\&M spending, cents per dollar public capital. \\
$y_{o}$ & 1.00 & GDP \\
$q x_{0}, q n_{0}$ & $0.54,0.46$ & Tradable and non-tradable share in output \\
$i x_{0}, i n_{0}$ & $0.082,0.0 .38$ & Gross sectoral investment shares \\
$i z 1_{0}, i z 2_{0}$ & $0.022,0.033$ & Gross public investment in 'bridges' and 'roads' \\
$c_{0}$ & 0.879 & Aggregate consumption (share of GDP) \\
$k x_{0}, k n_{0}, z e_{0}$ & $126.5,58.1$, & Initial capital stock in tradable, non-tradable and public sectors \\
$b_{o}, d_{o}, d c_{o}$ & $50,36,34$ & Initial (and target) debt levels: domestic, concessional and non-concessional external) \\
$r, r_{d}, r_{f}$ & $9.5,2,1.5$ & Initial interest rates (domestic, concessional and world risk-free interest rate) \% p.a. \\
$\nu_{g}, \eta_{g}$ & $7.0,3.0$ & Public external debt risk premium parameters \\
\hline
\end{tabular}




\begin{tabular}{ccl} 
Baseline values & Values & Definition \\
\hline$g$ & 1.5 & Exogeneous trend growth rate (\% p.a.) \\
$\bar{z}$ & {$[0,0.25]$} & Threshold in public capital \\
$h$ & 20 & Consumption tax rate (\% consumption) \\
$\theta_{w}$ & 0.10 & Wage tax (\% gross wages) \\
$\theta_{x}, \theta_{n}$ & 0.10 & Profit tax (\% of profits) \\
$\bar{l}, \bar{q}$ & $2.5,2.5$ & Efficient O\&M spending, cents per dollar public capital. \\
$y_{o}$ & 1.00 & GDP \\
$q x_{0}, q n_{0}$ & $0.54,0.46$ & Tradable and non-tradable share in output \\
$i x_{0}, i n_{0}$ & $0.082,0.0 .38$ & Gross sectoral investment shares \\
$i z 1_{0}, i z 2_{0}$ & $0.022,0.033$ & Gross public investment in 'bridges' and 'roads' \\
$c_{0}$ & 0.879 & Aggregate consumption (share of GDP) \\
$k x_{0}, k n_{0}, z e_{0}$ & $126.5,58.1$, & Initial capital stock in tradable, non-tradable and public sectors \\
$b_{o}, d_{o}, d c_{o}$ & $50,36,34$ & Initial (and target) debt levels: domestic, concessional and non-concessional external) \\
$r, r_{d}, r_{f}$ & $9.5,2,1.5$ & Initial interest rates (domestic, concessional and world risk-free interest rate) \% p.a. \\
$\nu_{g}, \eta_{g}$ & $7.0,3.0$ & Public external debt risk premium parameters \\
\hline
\end{tabular}




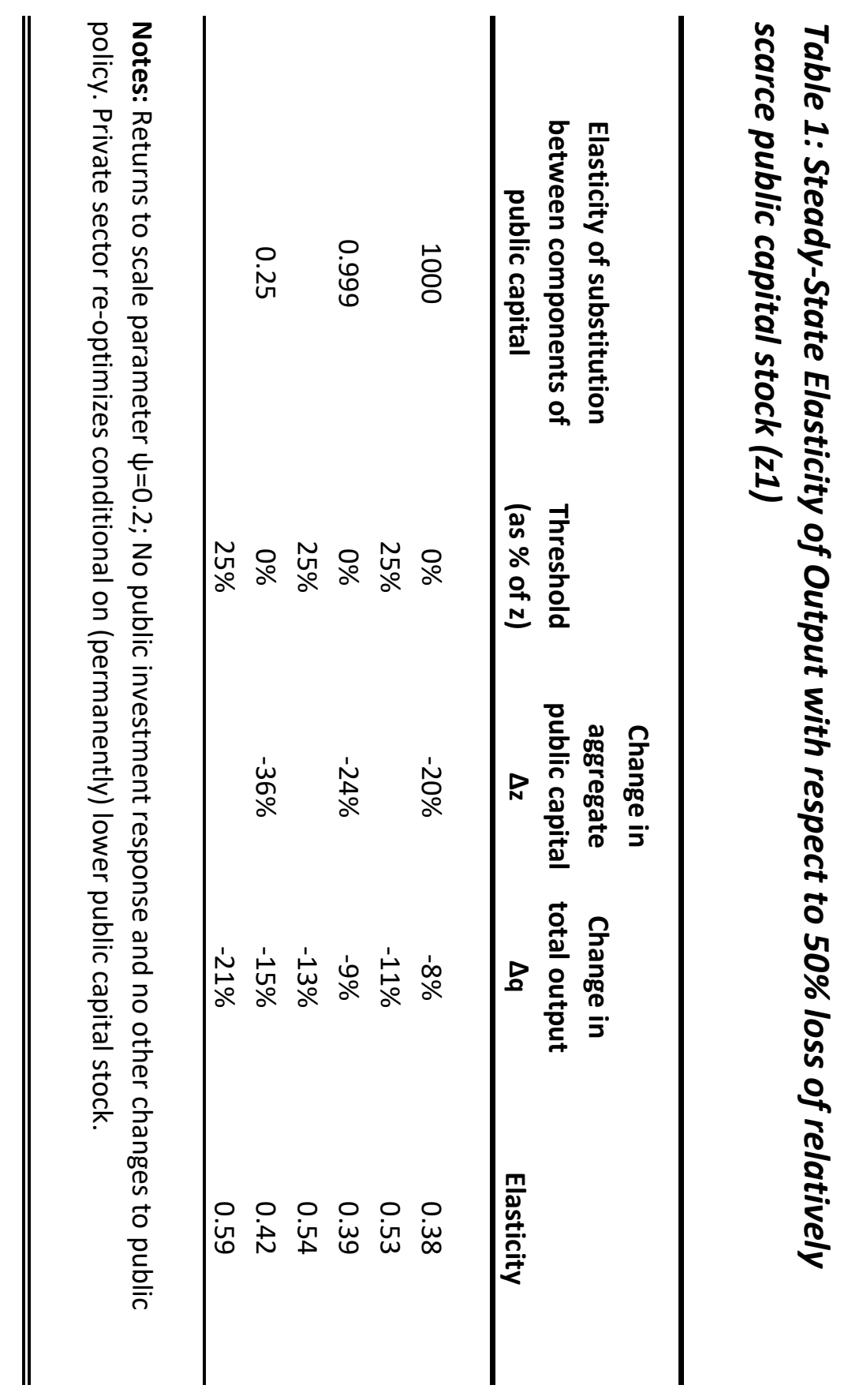




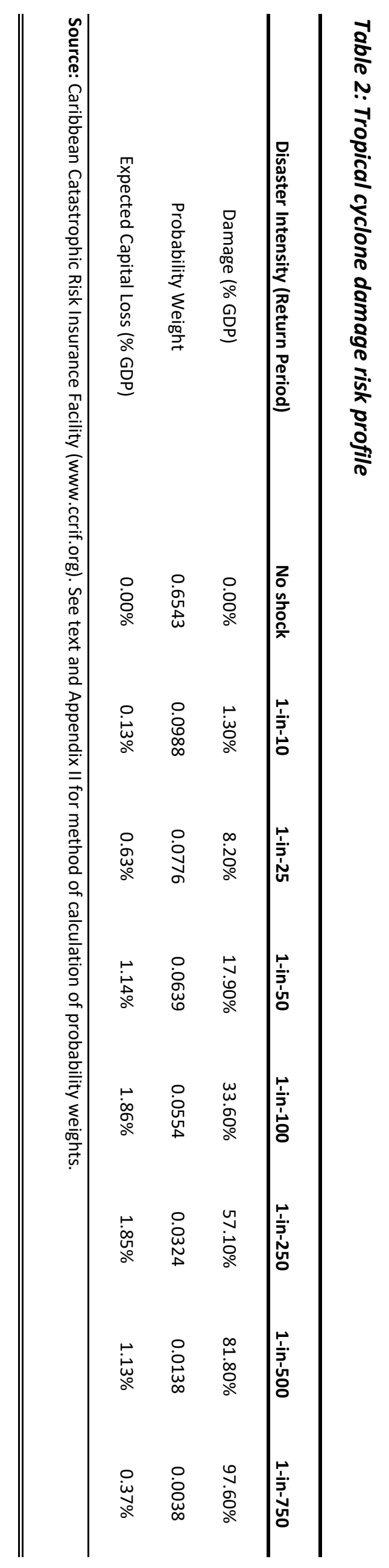




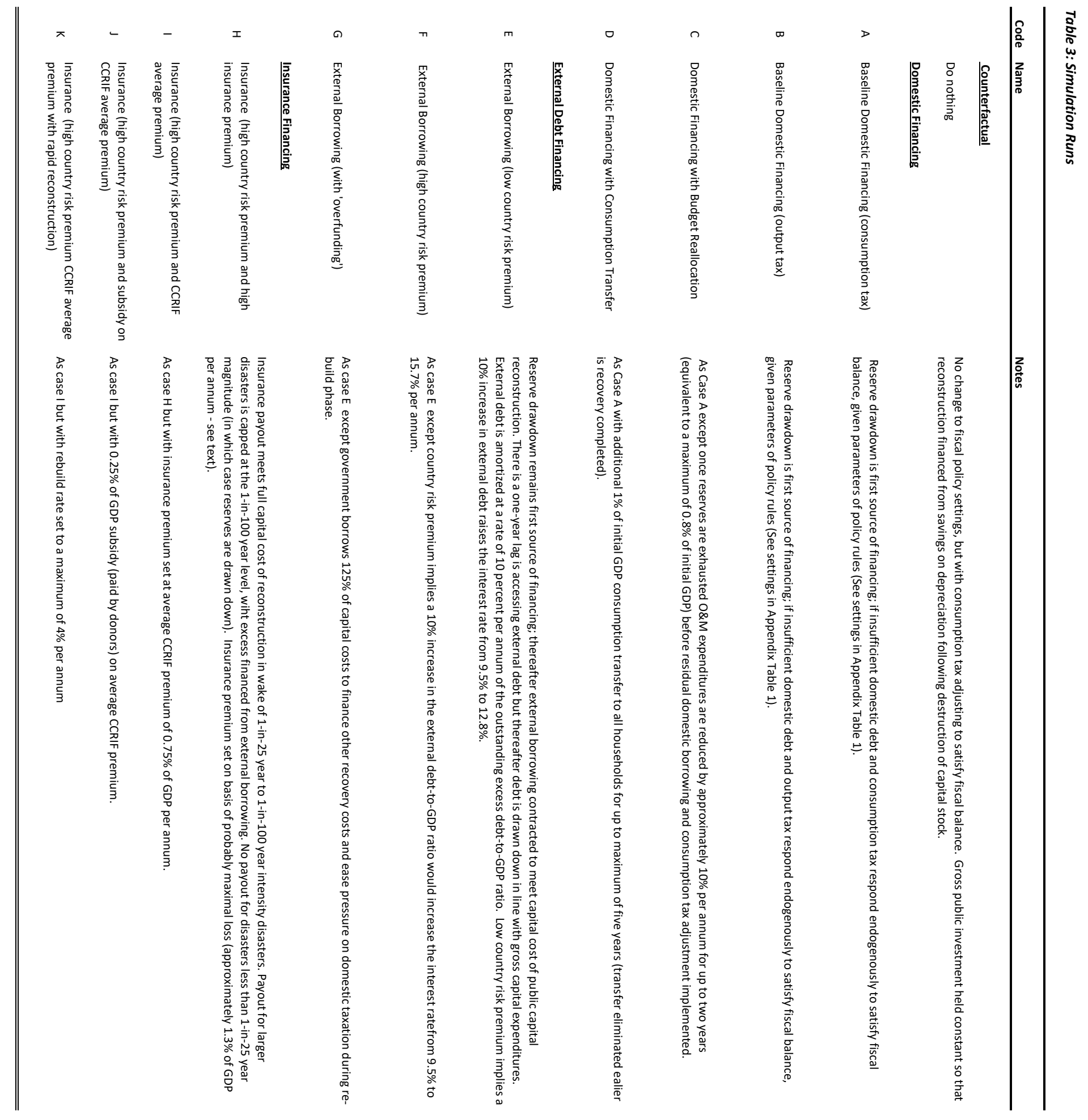




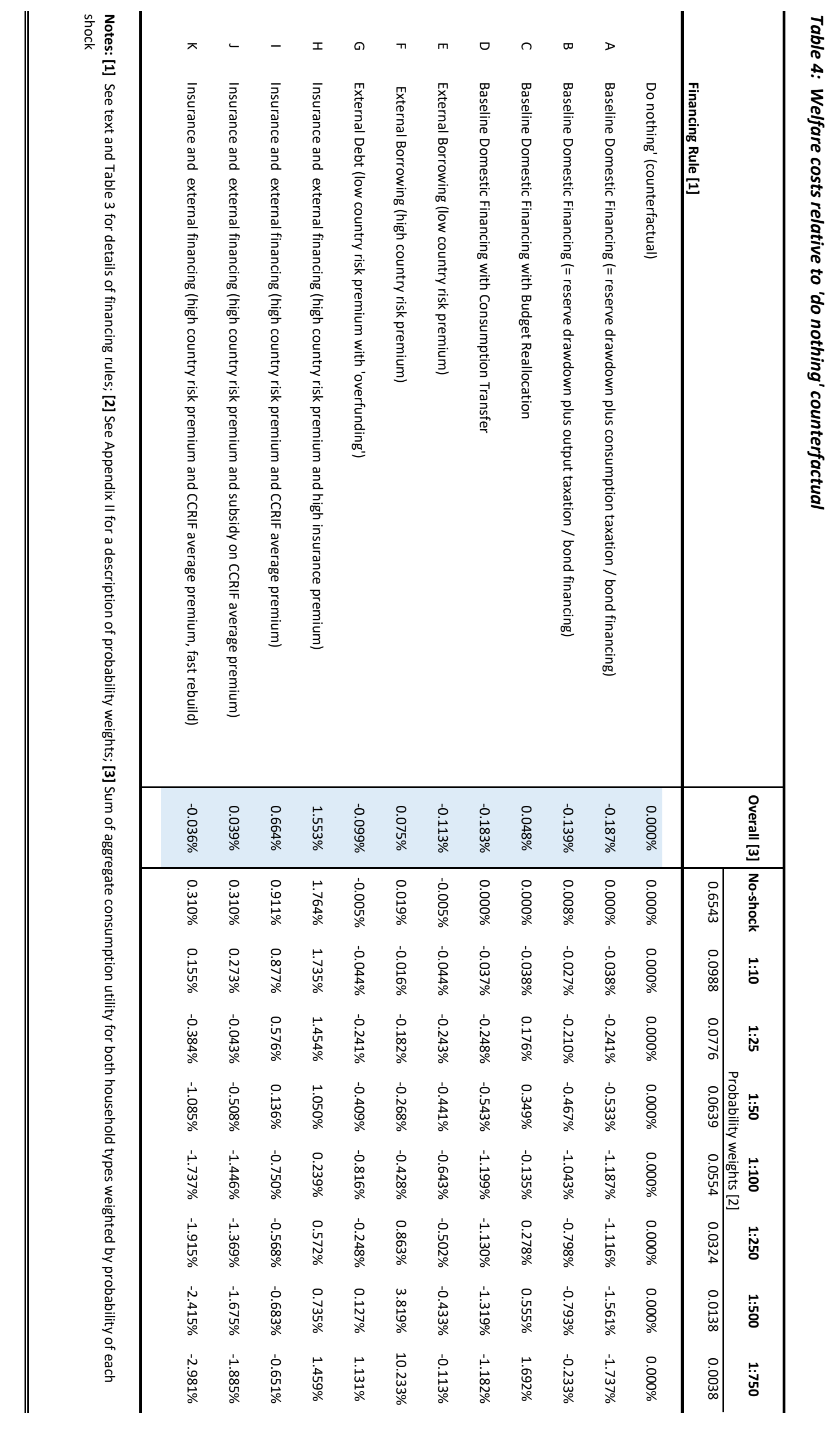




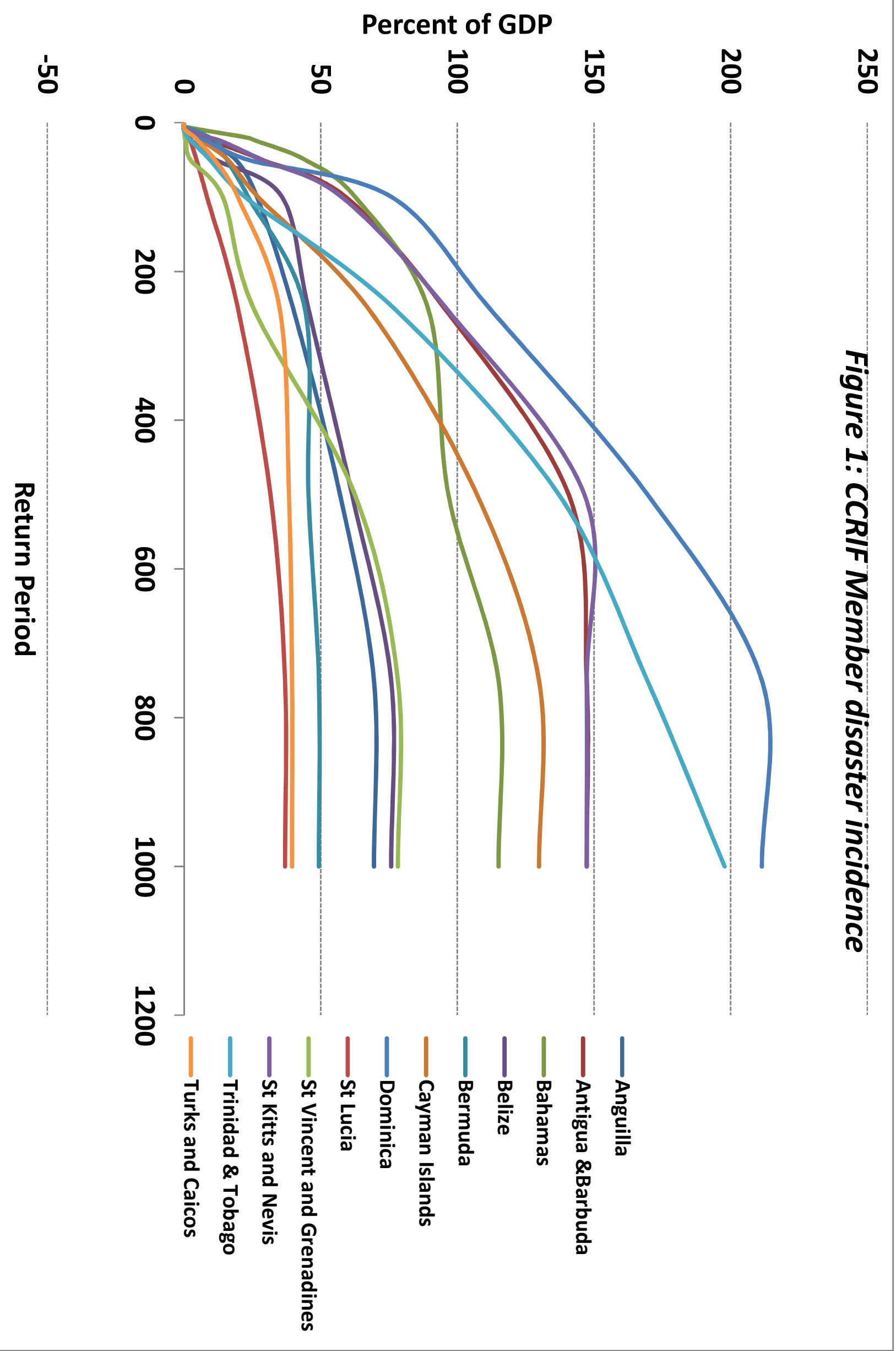




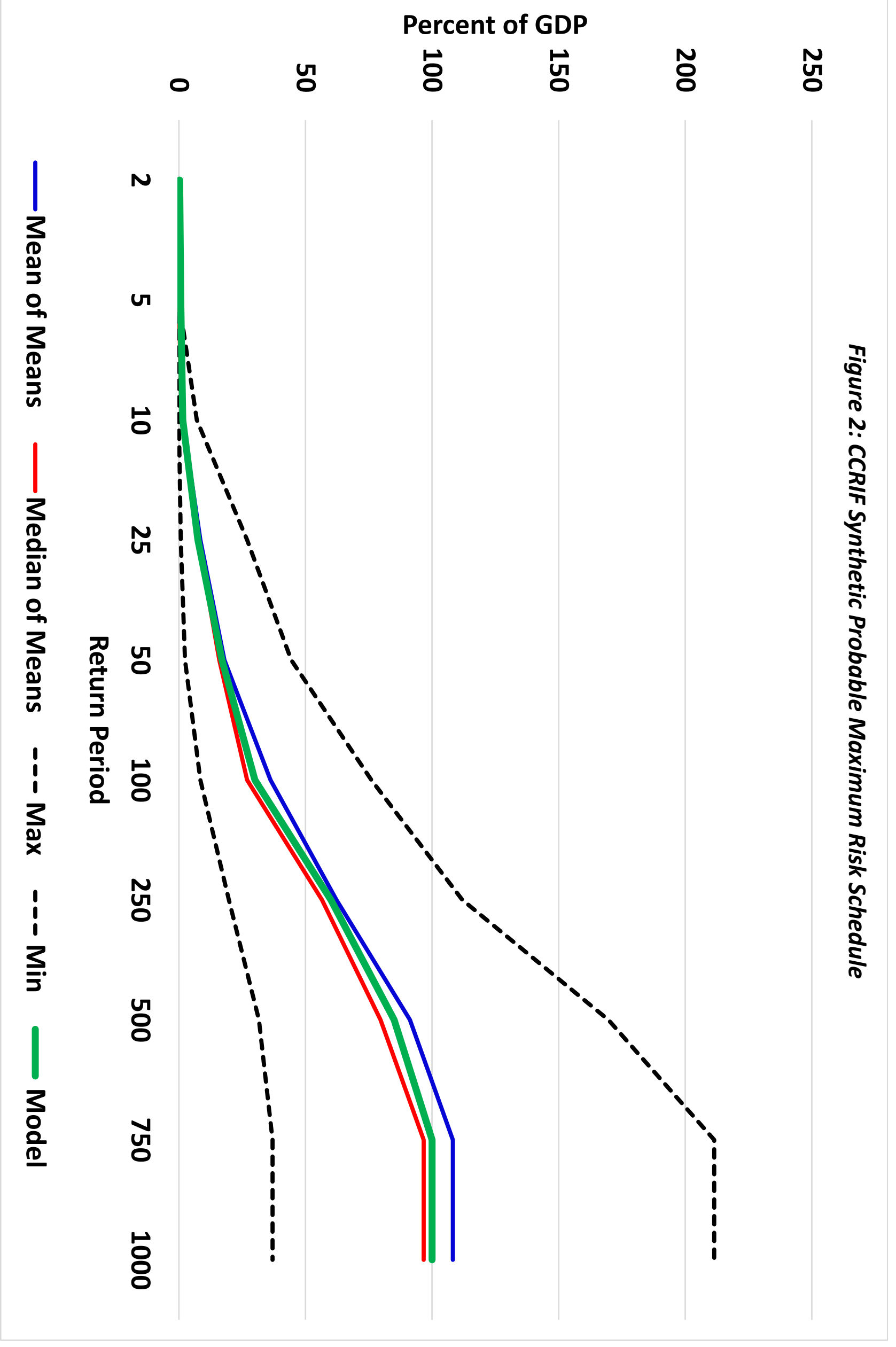



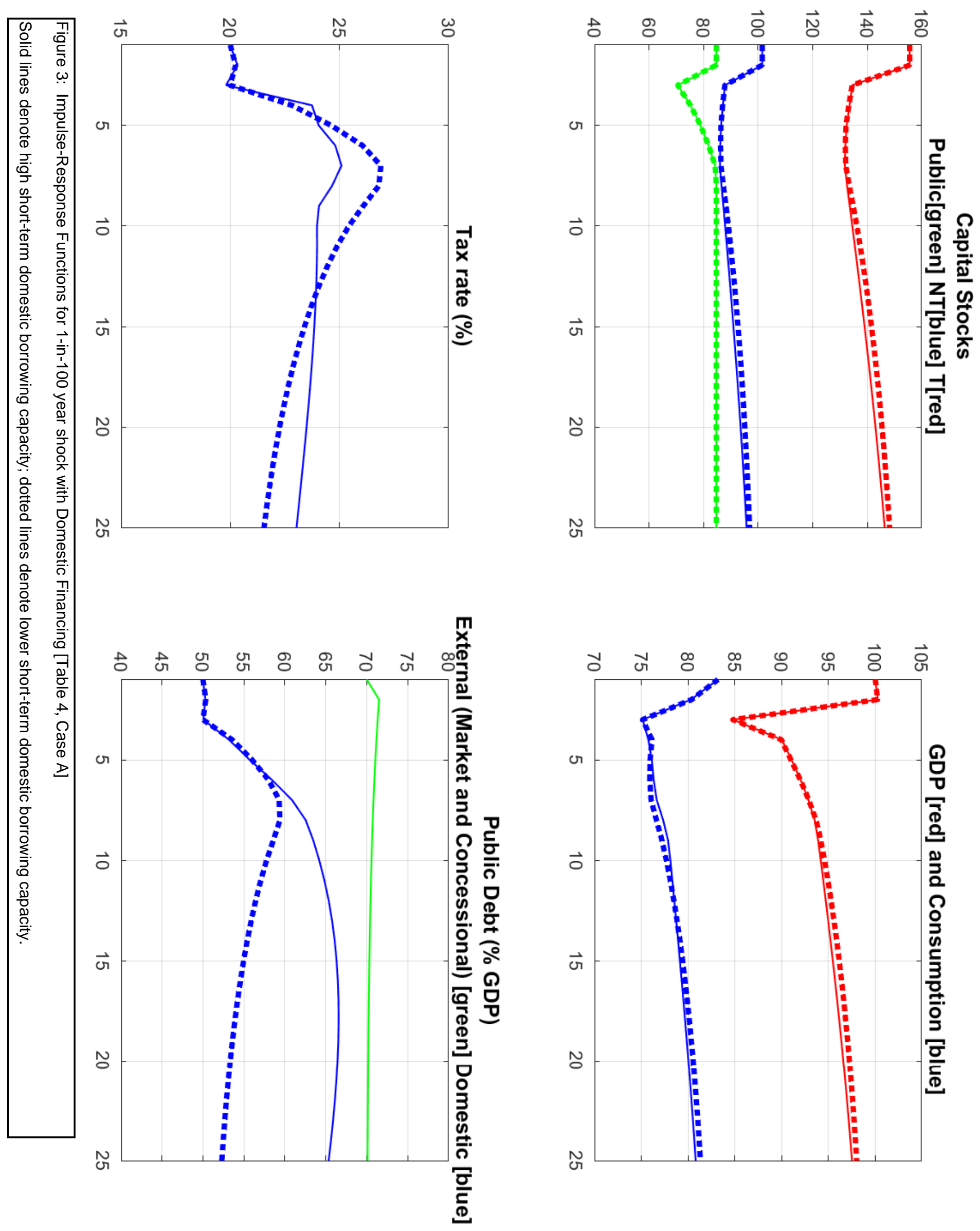

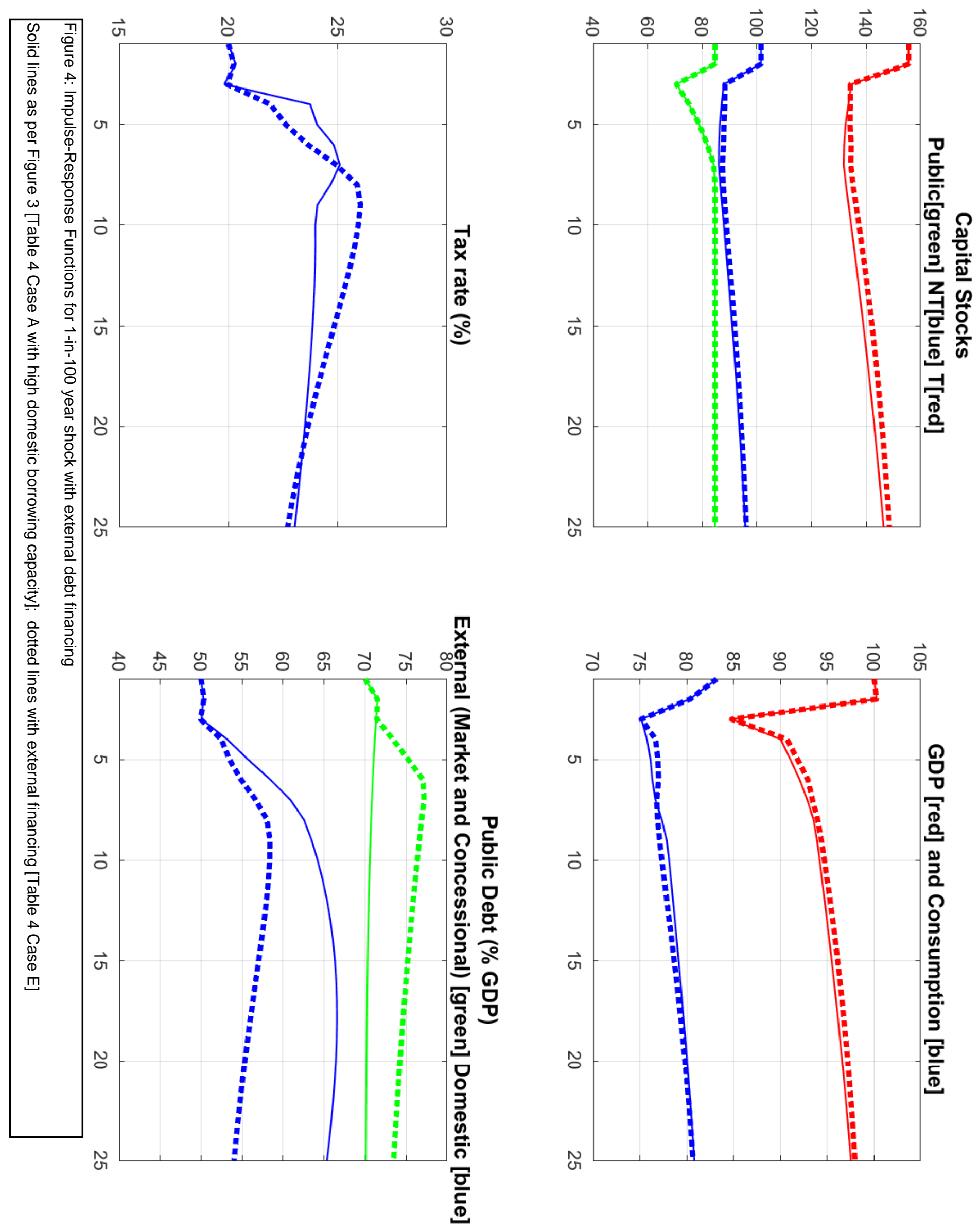

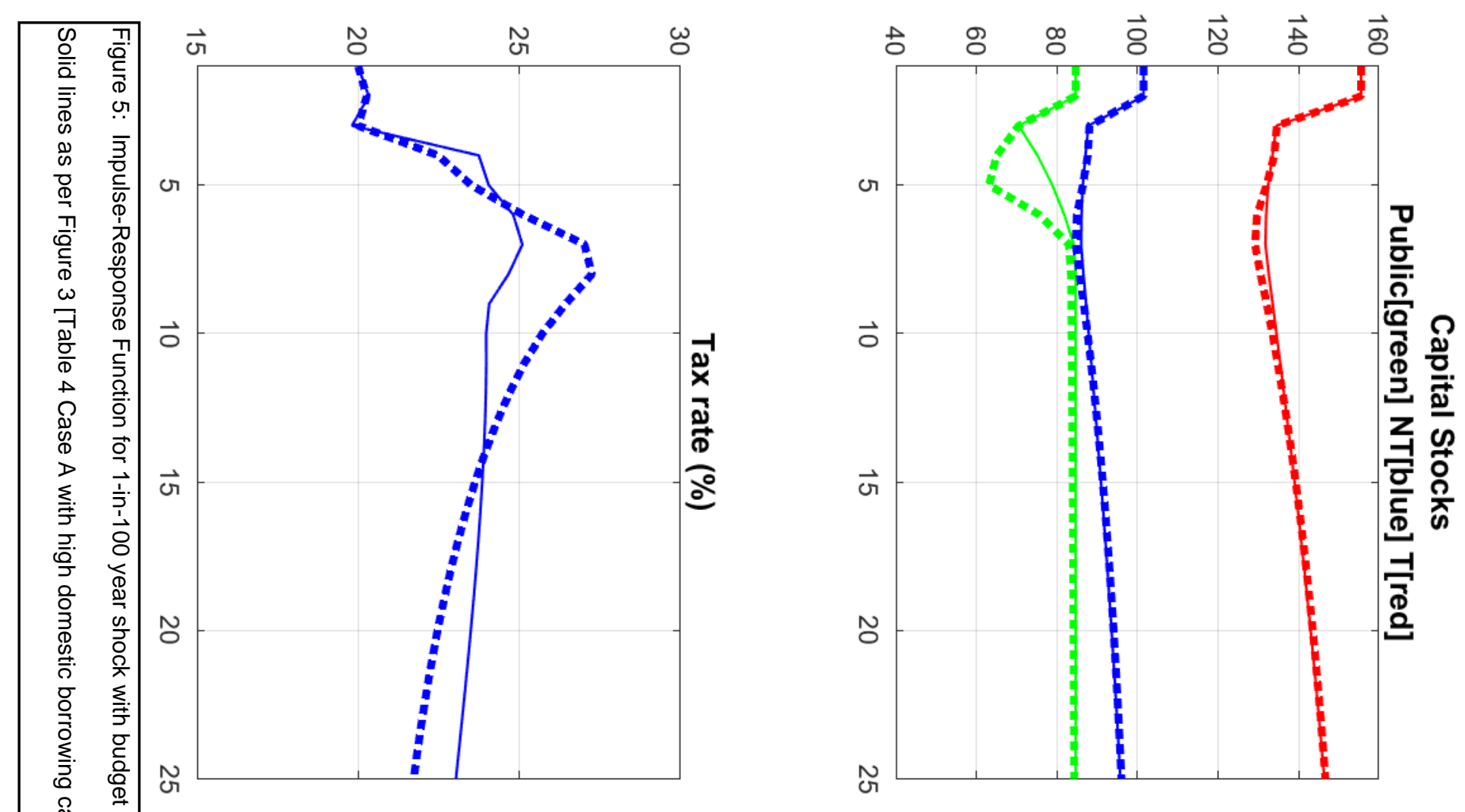

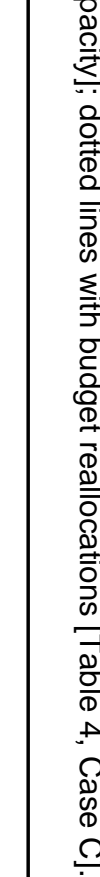




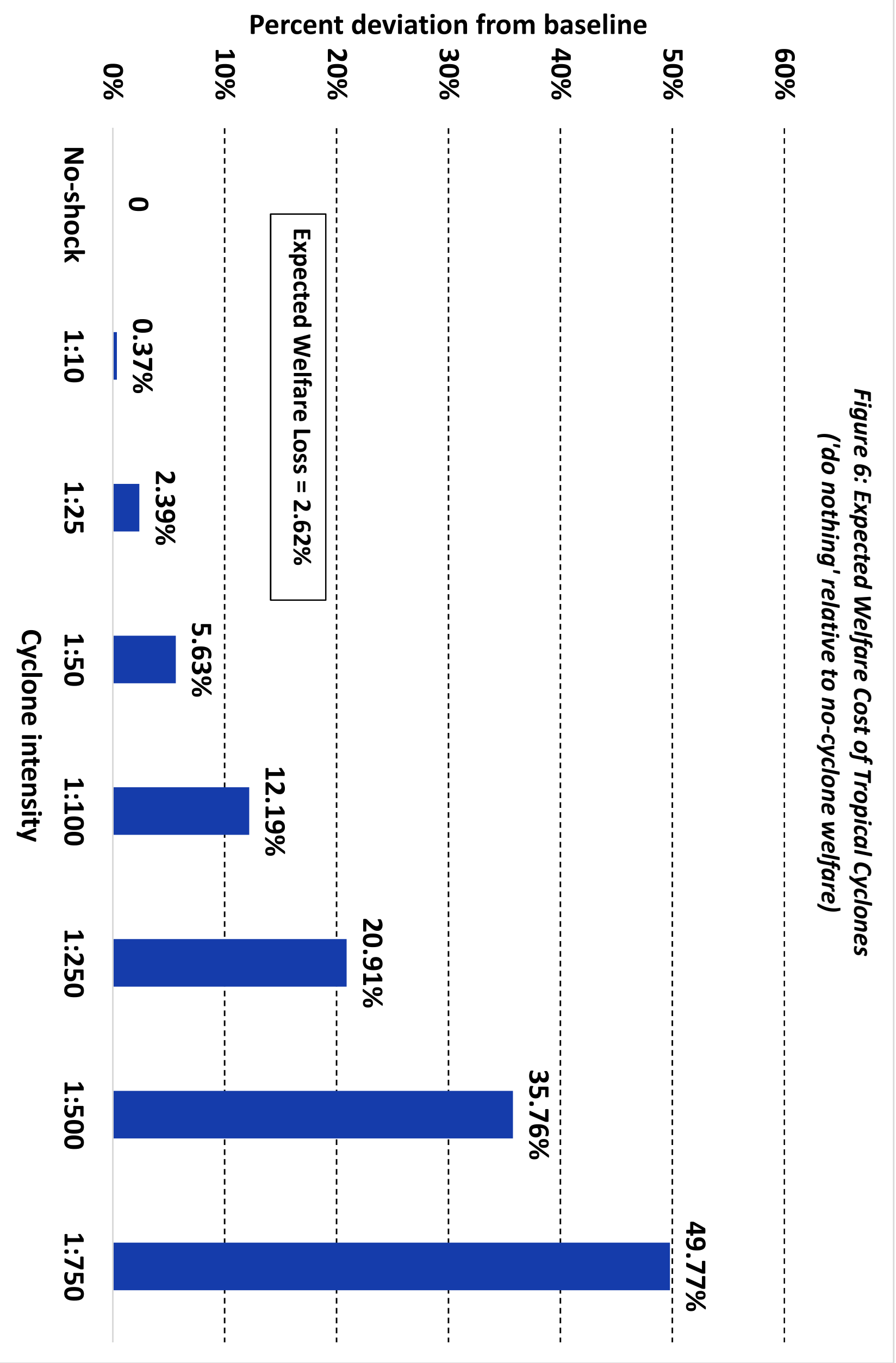



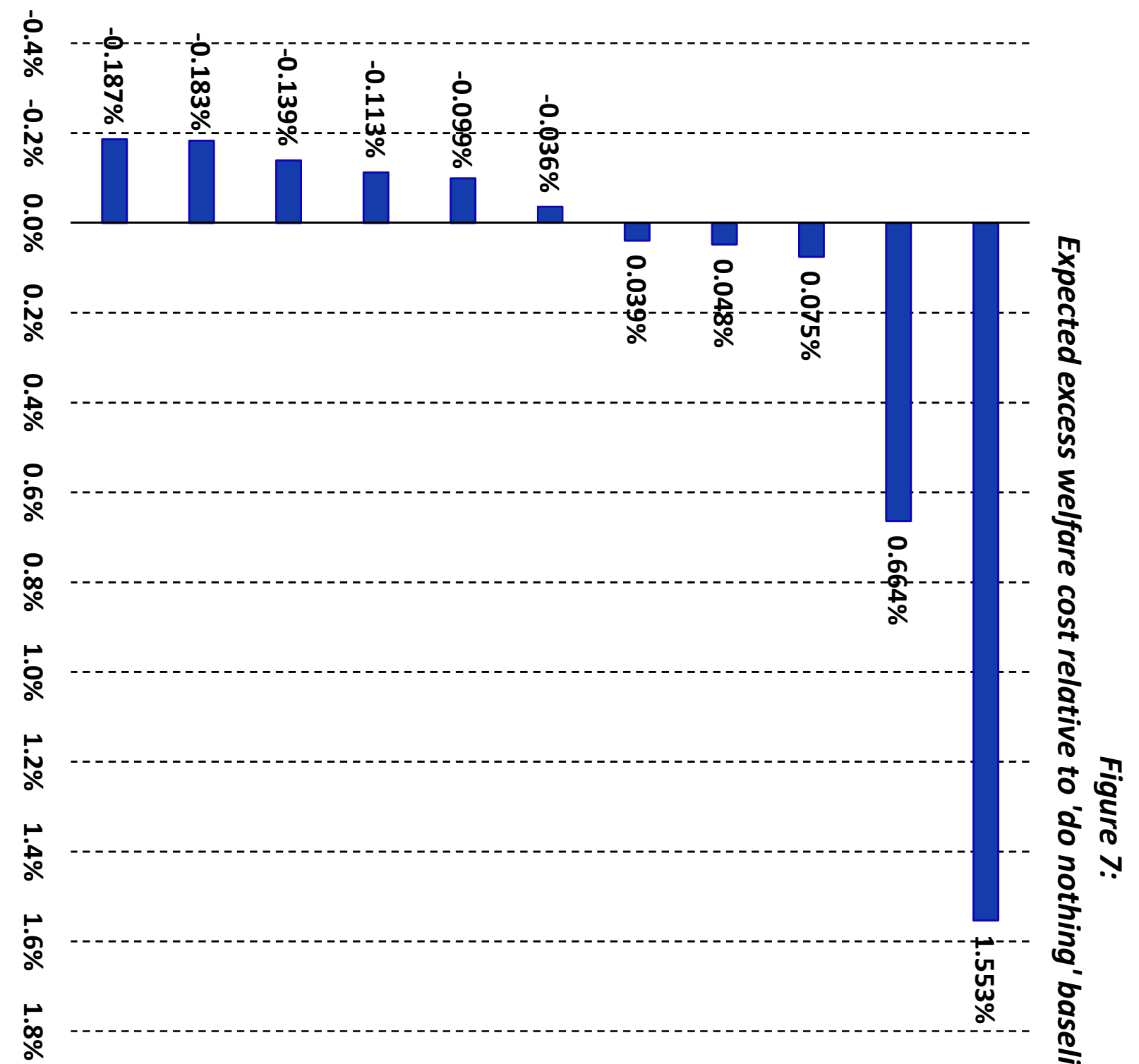

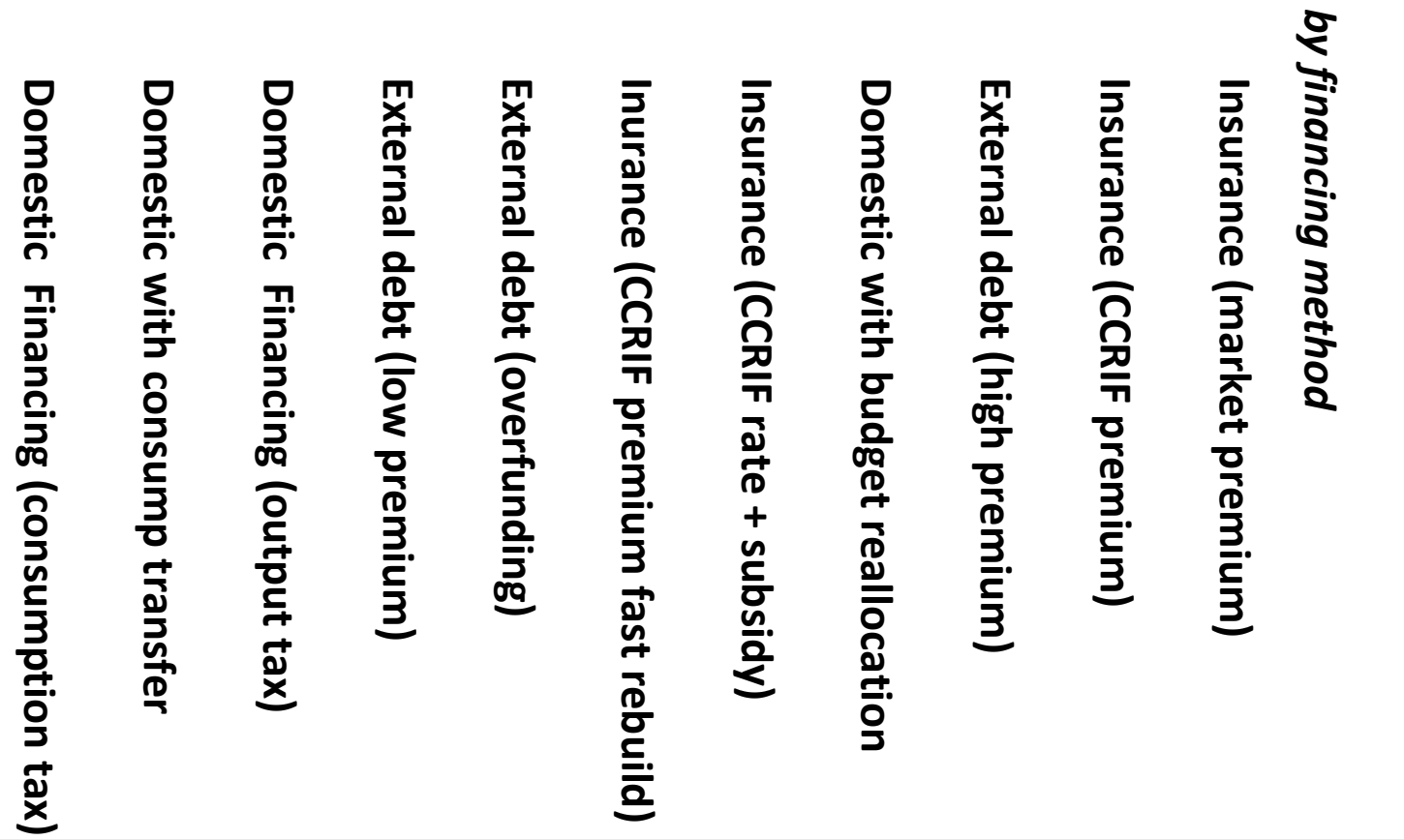




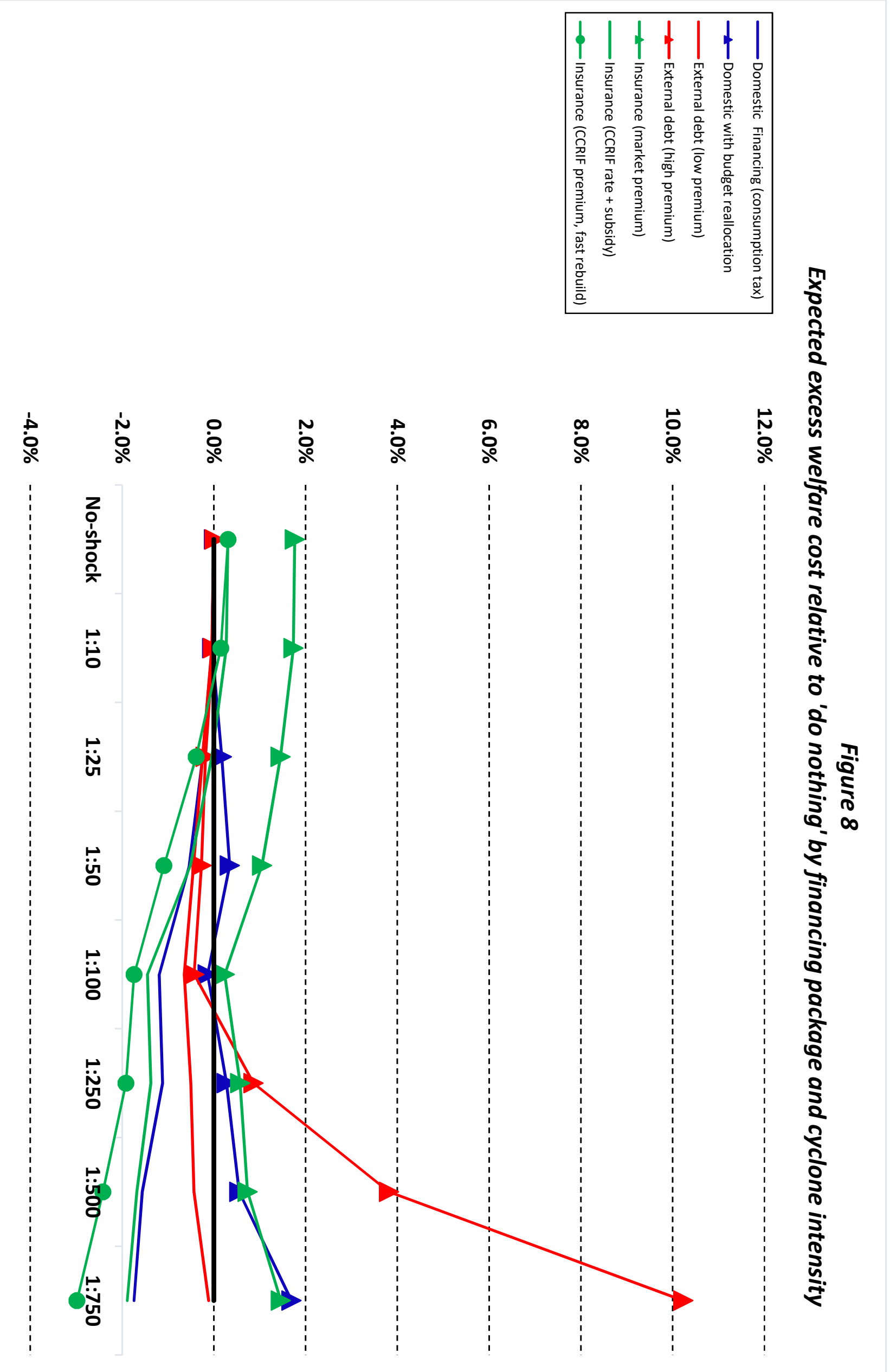

